\section{Q11}

10.

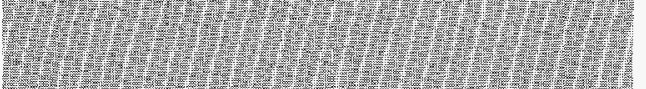

OAK RIDGE NATIONAL LABORATORY

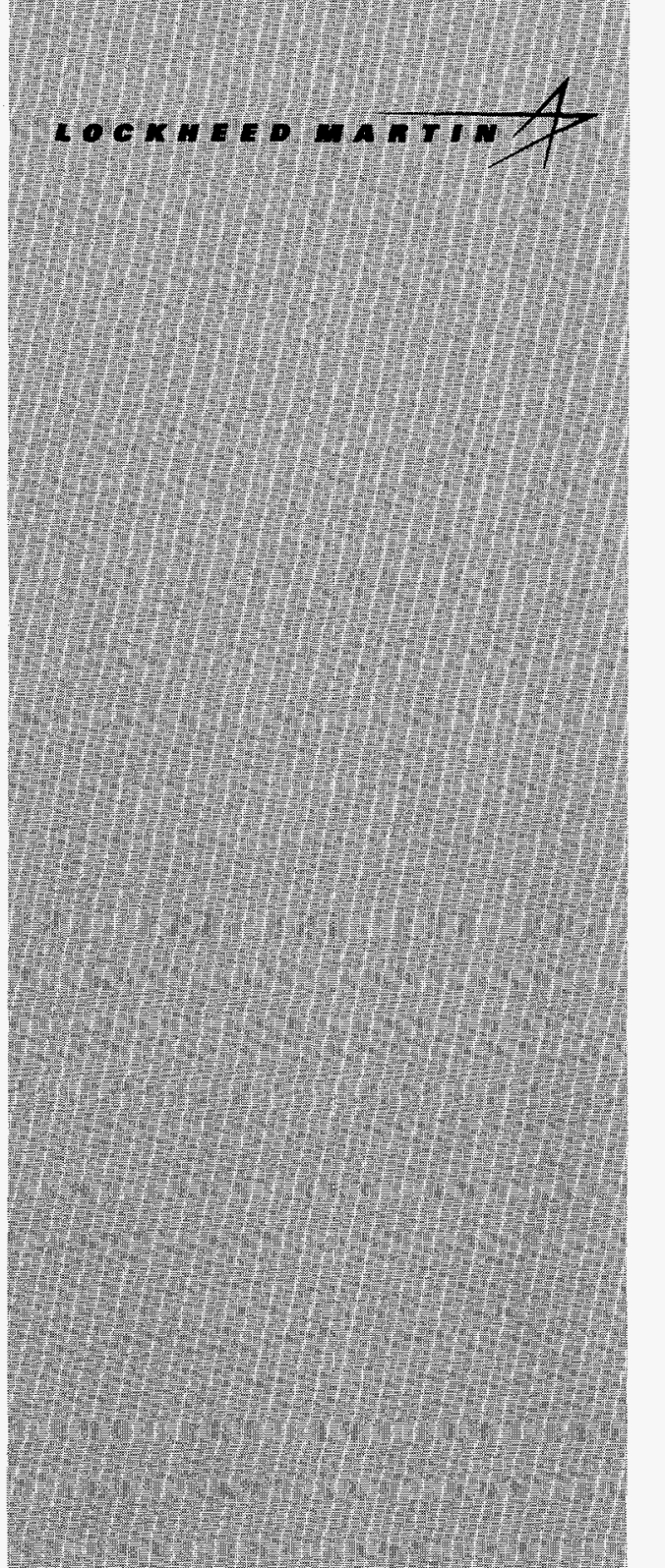

WAMAGED MNO OPERATED EY LOCKHEED WARTIU ENERGY RESEARCH CORPORATION FORTHE UNTED STATES DEPARMENT OF EVERGY
RECEIVET

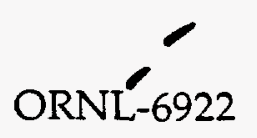

\section{REVIEW AND EVALUATION OF THE OFFICE OF SCIENCE AND TECHNOLOGY'S COMMUNITY LEADERS NETWORK}

\author{
Sam A. Carnes \\ Martin Schweitzer \\ Elizabeth B. Peelle
}


This report has been reproduced directly from the best available copy.

Available to DOE and DOE contractors from the Office of Scientific and Technical Information, P. O. Box 62, Oak Ridge, TN 37831; prices available from (423) 576-8401, FTS 626-8401.

Available to the public from the National Technical Information Service, U.S. Department of Commerce, 5285 Port Royal Road, Springfield. VA 22161.

This repor was prepared as an account of work sponsored by an agency of the United States Government. Neither the United States Government nor any agency thereof, nor any of their employees, makes any warranty, express or implied, or assumes any legal liability or responsibility for the accuracy. completeness, or usefulness of any information, apparatus, product, or process disclosed, or represents that its use would not infringe privately owned rights. Reference herein to any specific commercial product. process. or service by trade name. trademark, manufacturer, or otherwise, does not necessarily constitute or imply its endorsement, recommendation, or favoring by the United States Government or any agency thereof. The views and opinions of authors expressed herein do not necessarily state or reflect those of the United States Government of any agency thereof. 


\section{DISCLAIMER}

Portions of this document may be illegible electronic image products. Images are produced from the best available original document. 
ENERGY DIVISION

\title{
REVIEW AND EVALUATION OF THE OFFICE OF SCIENCE AND TECHNOLOGY'S COMMUNITY LEADERS NETWORK
}

\author{
Sam Carnes \\ Martin Schweitzer \\ Elizabeth Peelle \\ August 1997 \\ Sponsored by \\ Office of Science and Technology \\ Office of Environmental Management \\ U.S. Department of Energy \\ Prepared by the \\ OAK RIDGE NATIONAL LABORATORY \\ Oak Ridge, Tennessee 37831 \\ managed by \\ LOCKHEED MARTIN ENERGY RESEARCH CORP. \\ for the \\ U.S. DEPARTMENT OF ENERGY \\ under Contract Number DE-AC05-96OR22464
}





\section{ACKNOWLEDGMENTS}

The authors are grateful for the time and information provided by CLN's volunteer participants and Department of Energy and contractor staff in responding to questions during our interviews and responding to the written survey. We also appreciate the comments provided by the CLN leadership, DOE staff, and support contractors during the early phases of this research as we developed our approach and metrics for evaluating success.

As with much research, this evaluation was at least somewhat interpretive in nature and required synthesis among competing perspectives and recollections. Thus, there may be disagreements regarding some of the findings and conclusions. The findings and conclusions are those of the authors and may not represent those of the sponsoring organization nor of the CLN participants themselves. 



\section{TABLE OF CONTENTS}

ACKNOWLEDGMENTS $\ldots \ldots \ldots \ldots \ldots \ldots \ldots \ldots \ldots \ldots \ldots \ldots \ldots \ldots$ ii

TABLE OF CONTENTS $\ldots \ldots \ldots \ldots \ldots \ldots \ldots \ldots \ldots \ldots \ldots \ldots \ldots$

LIST OF TABLES $\ldots \ldots \ldots \ldots \ldots \ldots \ldots \ldots \ldots \ldots \ldots \ldots \ldots \ldots \ldots \ldots \ldots \ldots \ldots \ldots$

LIST OF FIGURES $\ldots \ldots \ldots \ldots \ldots \ldots \ldots \ldots \ldots \ldots \ldots \ldots \ldots \ldots \ldots \ldots \ldots \ldots \ldots \ldots \ldots$

EXECUTIVE SUMMARY $\ldots \ldots \ldots \ldots \ldots \ldots \ldots \ldots \ldots \ldots \ldots \ldots \ldots \ldots \ldots \ldots$

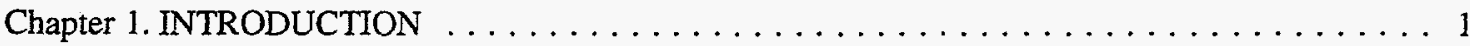

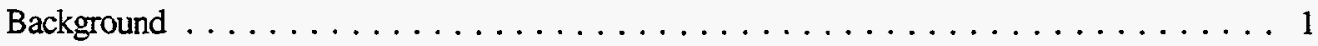

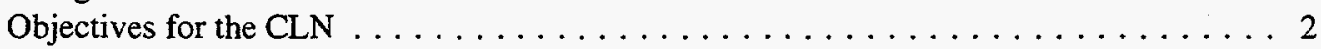

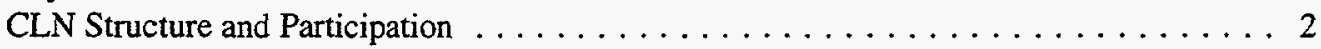

Scope of Report ............................... 2

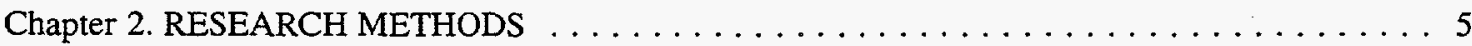

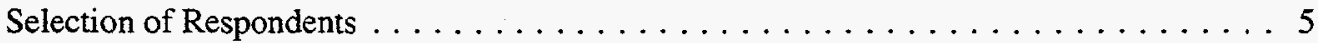

Data Collection ....................... 5

Data Analysis . . . . . . . . . . . . . . . . .

Chapter 3. THE CLN: ITS HISTORY, MISSION, AND ACTIVITIES $\ldots \ldots \ldots \ldots \ldots \ldots \ldots 11$

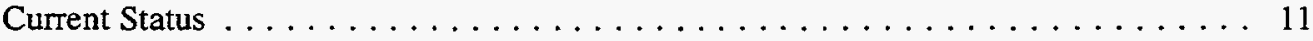

Mission and Charter ............................ 12

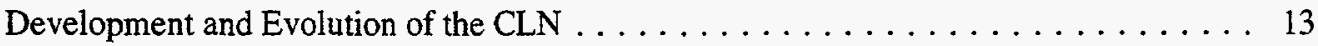

CLN Internal Organization . . . . . . . . . . . . . . . . 13

Activities . . . . . . . . . . . . . . . . . . . . 14

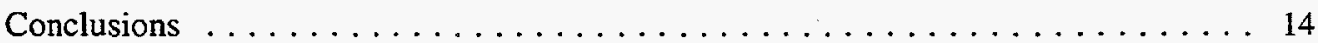

Chapter 4. PARTICIPANTS' PERCEPTIONS OF CLN $\ldots \ldots \ldots \ldots \ldots \ldots \ldots \ldots \ldots$

Interview Results . . . . . . . . . . . . . . . . . . . 17

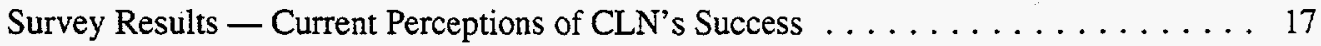

Changes in Perceived Success Over Time . . . . . . . . . . . . . . 22

Perceptions by Key Subsets of CLN Participants . . . . . . . . . . 25

Chapter 5. SUMMARY AND RECOMMENDATIONS $\ldots \ldots \ldots \ldots \ldots \ldots \ldots \ldots \ldots \ldots \ldots$

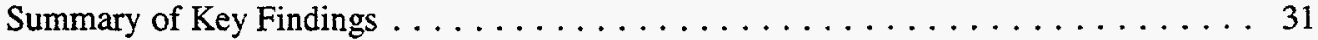

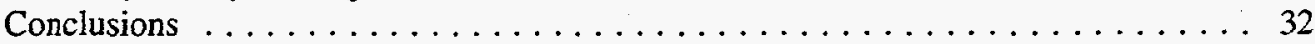

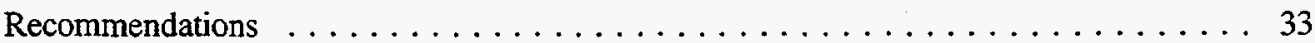

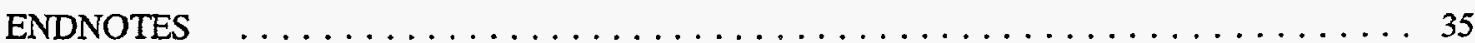

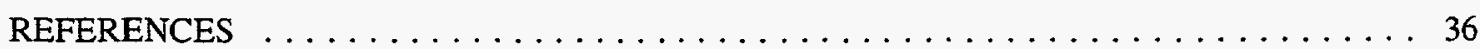

APPENDIX A. LIST OF RESPONDENTS AND ORGANIZATIONAL AFFILIATIONS $\ldots \ldots \ldots 37$

APPENDIX B. ORAL INTERVIEW PROTOCOL $\ldots \ldots \ldots \ldots \ldots \ldots \ldots \ldots \ldots \ldots \ldots$

APPENDIX C. WRITTEN SURVEY $\ldots \ldots \ldots \ldots \ldots \ldots \ldots \ldots \ldots \ldots \ldots \ldots \ldots \ldots$ 


\section{LIST OF TABLES}

Table 2.1 Performance indicators to measure usefulness of CLN according to each major objective $\ldots 8$

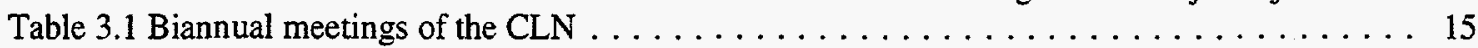

Table 4.1 Mean responses to all survey items by CLN participants and Focus Area staff . . . . . . 19

Table 4.2 Mean changes over time for CLN participants and Focus Area staff . . . . . . . . . . 24

Table 4.3 CLN participants' survey responses, by primary organizational affiliation $\ldots \ldots \ldots 27$

Table 4.4 CLN participants' survey responses, by Focus Area involvement . . . . . . . . . . 29

\section{LIST OF FIGURES}

Fig. 2.1 Primary organizational affiliation of CLN participants $\ldots \ldots \ldots \ldots \ldots \ldots \ldots$

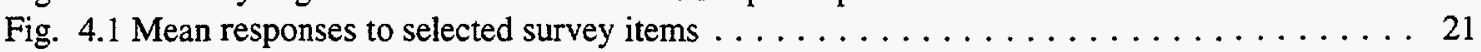

Fig. 4.2 Mean responses to survey items addressing Focus Area involvement $\ldots \ldots \ldots \ldots \ldots 23$

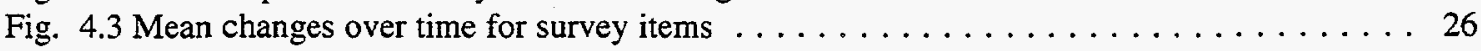




\section{EXECUTIVE SUMMARY}

This report constitutes a review and evaluation of the Community Leaders Network (CLN), an informally structured national stakeholder group sponsored by the Department of Energy (DOE) Environmental Management (EM) Program's Office of Science and Technology (OST) to obtain citizen input into the technology research and development programs of the OST. Since the CLN's inception in 1993, its participants, currently numbering about 35 members mostly from jurisdictions hosting DOE waste management and environmental remediation sites, and its clients (i.e., OST) have invested substantial resources to develop the capability to enhance technology development and deployment activities through proactive stakeholder involvement. The specific objectives of the CLN are to:

- provide feedback and input to OST on technology development activities,

- provide information on OST ideas and approaches to key stakeholder groups, and

- provide input to OST on stakeholder concerns and involvement

The CLN's activities have necessitated significant commitments of time by both the participants and DOE and contractor staff to learn about DOE's waste management and environmental remediation problems, how those problems are viewed by DOE's many stakeholders, and how technologies might be developed to simultaneously assist in solving those problems and be responsive to other stakeholder concerns and interests.

Recognizing the need to assure that the resources volunteered by OST's stakeholders (i.e., their time) and spent by OST and its contractors (i.e., public monies) constitute a wise investment and, if possible, to enhance the return on that investment, OST identified the need for an objective, independent, and defensible review and evaluation of the CLN's activities and OST's oversight and management of those activities.

The worth of any evaluation rests upon the metrics of success and failure. Building upon prior recommendations regarding approaches to evaluating public and stakeholder involvement activities of
DOE's Office of Environmental Management (Carnes, Schweitzer, Peelle, Wolfe, and Munro 1996), and with a special emphasis on the effectiveness and efficiency of the CLN, we developed performance indicators for the CLN related to its mission and objectives (see Table ES.1). The development of these indicators was also based on a thorough review of materials related to the CLN and its activities since its inception and iterative consultations with OST and the CLN leadership.

Values for these performance indicators were collected through interviews with and surveys administered to CLN participants and representatives of OST's staff charged with the responsibility of developing technologies to solve major classes of DOE's legacy waste problems. These classes of problems correspond to OST's four Focus Areas (FAs) and include storage tanks, mixed waste, subsurface contaminants, and decontamination and decommissioning of surplus facilities. The research data were analyzed to assess the CLN's effectiveness and efficiency and to identify what has worked, what has not worked, and what might be done to improve the effectiveness and efficiency of the CLN and OST's use of the CLN in accomplishing its mission and objectives.

According to CLN participants themselves and representatives of OST's FAs, the CLN has succeeded. Its attention to national, high-level, integrated policy issues, its attention to FAs for site input to problem solving, and its concern about the interplay between top-down and bottomup communications and decision-making have all been hallmarks of the organization.

The future success of the CLN may depend on how a number of issues and concerns are addressed in the near future.

1. It is very important to make wise use of volunteer time and resources. The value of the expertise that OST has obtained from individual CLN participants would be significant in any case; the value of the expertise that OST has obtained from the CLN - the collective experience of CLN participants with OST and Focus Areas - is much greater. In many ways, the CLN represents an 


\section{Table ES.1. Performance indicators to measure usefulness of CLN according} to each major objective

\section{Provide feedback and input to OST on technology development activities}

- Participants' evaluation of how well CLN participants represent all important stakeholder groups

- Participants' evaluation of the effects of CLN activities on the legitimacy of the process used by OST to make decisions on technology development activities

- Participants' evaluation of the effect of CLN activities on the legitimacy of OST decisions

- Participants' evaluation of the extent to which CLN activities have added to OST's understanding of the interests and concerns of key stakeholders

- Participants' evaluation of the effect of CLN activities on their trust and confidence in OST and its contractors

- Participants' evaluation of the effect of CLN activities on the quality of key OST decisions

- Participants' evaluation of how CLN activities have affected the speed at which new technologies that address important EM site needs are introduced and implemented

- Participants' evaluation of how CLN activities have affected the public acceptability of new technologies that address important EM site needs

- Participants' evaluation of how their involvement in Focus Areas has affected the CLN's ability to provide feedback and input to OST on technology development activities

- Participants' comparison of the usefulness of Focus Area involvement with the usefulness of CLN's other activities as a means of providing feedback and input to OST on technology development activities

\section{Provide information on OST ideas and approaches to key stakeholder groups}

- Participants' evaluation of the extent to which CLN activities have added to key stakeholder groups' understanding of OST's interests, concerns, and programs

- Participants' evaluation of how their involvement in Focus Areas has affected the CLN's ability to provide information on OST ideas and approaches to key stakeholder groups

- Participants' comparison of the usefulness of Focus Area involvement with the usefulness of CLN's other activities as a means of providing information on OST ideas and approaches to key stakeholder groups

\section{Provide input to OST on stakeholder concerns and involvement}

- List of public involvement programs/efforts on which CLN has provided input to OST

- Participants' evaluation of the value of information on stakeholder interests and priorities provided to OST by CLN

- Participants' evaluation of the value of information on designing and implementing stakeholder involvement efforts that CLN has provided to OST

- Participants' evaluation of how their involvement in Focus Areas has affected the CLN's ability to provide input to OST on stakeholder concerns and involvement

- Participants' comparison of the usefulness of Focus Area involvement with the usefulness of CLN's other activities as a means of providing input to OST on stakeholder concerns and involvement 
institutional memory that is quite distinct from the remainder of OST's institutional memory but equally valid, long-lasting, and important.

2. The kinds and amounts of support services needed by the CLN and its participants are both important and, consistent with the increasing assumption of leadership by CLN participants, may best be identified by the CLN participants themselves. The CLN participants are busy volunteers with significant experience as volunteers and, in all cases, as professionals in what they do. These volunteers have already indicated their willingness to work, and they likely know best the kinds of support they need to make best use of their time.

3. If there were notes of caution and discomfort from the CLN participants, they tended to relate to a lack of attention by OST to their recommendations or inadequate feedback regarding the worth of their deliberations. This failure by the OST leadership to communicate back to the CLN participants may be characteristic of the informality and flexibility of the CLN, but it is a characteristic that is not conducive to success.

4. The CLN participants and some FA representatives focused on the need for better definition, integration, and coordination of stakeholder involvement activities within OST. There was certainly ample agreement regarding the need for coordination between the CLN and the site technology coordinating groups (STCGs), even recognizing the technically legitimate need to protect the indedpendence of the latter groups as field-, rather than headquarters-directed activities.

5. As EM-50 begins its Technology Deployment Initiative (TDI), it would be prudent to reconsider the structure and activities of the CLN, the CLN FA subgroups, and other stakeholder involvement mechanisms (e.g., STCGs, SSABs, and the EMAB). Technology deployment has different stakeholder involvement needs than does technology development. More of the emphasis will inevitably be on acceptance of the developed technology by stakeholders - regulators and other stakeholders having influence over regulators. In a sense, at least for the TDI, the opportunity for stakeholder involvement in the design and development of technology has passed, although it may still be possi- ble for the CLN and other stakeholders to provide input to the permitted version of a technology.

6. As a mature stakeholder group, the CLN and its members should be asked how they would like the CLN to work, operate, and evolve in the future. Although OST cannot abandon its responsibility or accountability for OST activities or even for the CLN, it should be acknowledged that the CLN and its members now have significant institutional memory as compared with OST and the remainder of EM. OST might invite CLN participants to work with OST and the FAs to develop program plans and budgets for all CLN activities.

7. There are other improvements needed that may be outside the scope of OST. These include the definition and clarification of the roles of the CLN, the STCGs, the SSABs, the Environmental Management Advisory Board (EMAB), and the sites for stakeholder involvement for all EM activities, and the need for better communications among stakeholders at DOE sites with different programmatic sponsors or landlords (e.g., EM, Defense Programs, and Energy Research). 


\section{INTRODUCTION}

This report constitutes a review and evaluation of the Community Leaders Network (CLN), an informally structured national stakeholder group sponsored by the Department of Energy (DOE) Environmental Management (EM) Program's Office of Science and Technology (OST) (previously the Office of Technology Development, or OTD) to obtain citizen input into the technology research and development programs of the OST. Since the CLN's inception in 1993, its participants and sponsor (i.e., OST) have invested substantial resources, in time and money, in developing the capability to enhance technology development and deployment activities through proactive stakeholder involvement. These activities have necessitated significant commitments of time by both the participants and DOE and contractor staff to learn about DOE's waste management and environmental remediation problems, how those problems are viewed by DOE's many stakeholders, and how technologies might be developed to simultaneously assist in solving those problems (i.e., actually disposing of wastes and remediating contamination) and be responsive to other stakeholder concerns and interests.

Although both the CLN's participants and its sponsor have periodically addressed the CLN's operation and its effectiveness, to date, there has been no comprehensive nor systematic evaluation and review of the CLN and its operation and effectiveness. Recognizing the need to assure that the resources volunteered by OST's stakeholders (i.e., their time) and spent by OST and its contractors (i.e., public monies) constitute a wise investment and, if possible, to enhance the return on that investment, OST identified the need for an objective, independent, and defensible review and evaluation of the CLN's activities and OST's oversight and management of those activities.

The worth of any evaluation rests upon the metrics of success and failure. Building upon recommendations provided to DOE's Office of Intergovernmental and Public Accountability related to the attributes of successful public and stakeholder involvement and performance indicators for those attributes (Carnes, Schweitzer, Peelle, Wolfe, and Munro 1996), and with a special emphasis on the effectiveness and efficiency of the CLN, we devel- oped performance indicators for the CLN related to its mission and objectives. The development of these indicators was also based on a thorough review of materials related to the CLN and its activities since its inception and iterative consultations with OST and the CLN leadership.

Data pertaining to these performance indicators were collected through interviews with and surveys administered to CLN participants and a purposive sample of the OST (see Chapter 2). The research data were analyzed to assess the CLN's effectiveness and efficiency and to identify what has worked, what has not worked, and what might be done to improve the effectiveness and efficiency of the CLN and OST's use of the CLN in accomplishing its mission and objectives.

\section{BACKGROUND}

The CLN, with participation from approximately 35 individuals from across the country, assists OST by providing individual inputs on, and reviews of, technology development issues and initiatives. The CLN is not a consensus-seeking body and is not chartered under the Federal Advisory Committee Act (FACA); rather, OST intends for the CLN to provide a range of individual opinions from a variety of stakeholders and facilitate information exchange. This informal structure of the CLN also is intended to allow the group's role to evolve to accommodate changes in management approach or direction by OST.

The mission of OST is to manage and direct targeted basic research and focused, solution-oriented technology development programs to support the DOE Office of Environmental Management (EM). OST programs involve research, development, demonstration, testing and evaluation activities designed to produce innovative technologies and technology systems to meet national needs for regulatory compliance, lower life-cycle costs, and reduced risks to the environment and to public health. The major customers for innovative science and technology are the operational offices within EM - Waste Management; Nuclear Material and Facility Stabilization; and Environmental Restoration. On average, the annual budget of EM has been approximately one-third of total DOE budget (about $\$ 6$ 
billion of $\$ 18$ billion), and the annual budget of OST has been on the order of approximately $\$ 300$ million, or five percent of the total EM budget.

Initially, the CLN focused on OST's Integrated Demonstration activities. Its role has changed, however, as EM instituted a new management strategy emphasizing four major remediation and waste management Focus Areas (FA) within the DOE weapons complex. These FAs include

- Mixed Waste Characterization, Treatment, and Disposal (MWFA);

- High-Level Waste Tank Remediation (TFA);

- Subsurface Contaminants (SCFA); and

- Facility Transitioning, Decommissioning, Final Disposition (D\&DFA).

These FAs currently function as one of the CLN's primary concerns as individual participants provide insights on technology development and deployment issues and contribute to OST's public and tribal participation activities and policy.

\section{OBJECTIVES FOR THE CLN}

The specific objectives for the CLN have evolved somewhat over time as activities and focus within OST has evolved. Currently, objectives for the CLN include

- Provide feedback and input to OST on technology development activities,

- Provide information on OST ideas and approaches to key stakeholder groups, and

- Provide input to OST on stakeholder concerns and involvement.

As elaborated in Chapter 2, these sets of objectives were used to develop performance indicators to ascertain the extent to which the CLN has met its objectives and to identify areas in which its operation could be improved.

\section{CLN STRUCTURE AND PARTICIPATION}

OST representatives are responsible for directing CLN input to DOE personnel and other interagency coordination groups and coordinating $\mathrm{DOE}$ response to individual CLN comments and recom- mendations. In addition, OST staff are responsible for negotiating with contractors providing support services to the CLN. CLN participants, as volunteers, are responsible for attending periodic meetings to review issues, exchanging information, and considering program needs. They are asked to provide meaningful input on technology development issues and assist with the development of OST's stakeholder involvement program as it relates to technology development. OST also intends for CLN participants to share information and materials from meetings with the communities or organizations they represent, and seek further recommendations from such constituencies.

Participants come from DOE sites dealing with issues related to the FAs and from appropriate national organizations. Initially invited to join the CLN based on recommendations from OTD Integrated Demonstration staff and public participation coordinators at DOE facilities, participants have been added to the CLN to ensure adequate geographic and FA representation. Community leaders, including, but not limited to, representatives of local, state, and tribal governments, environmental organizations, labor, industry, academia, and members of the public-at-large were invited to participate based on their involvement with technical, environmental, and public and tribal involvement issues at DOE sites, or as part of their work with national, regional, or community organizations. The current CLN roster includes participants from 15 states who have interest in or affiliation with DOE sites represented by approximately $10 \mathrm{DOE}$ field or operations offices.

\section{SCOPE OF REPORT}

This report, and the research from which it was prepared, reviews and evaluates the CLN and activities pursued by OST and its contractors to support and work with the CLN. It focuses on the CLN in the context of decision making and decision outcomes related to OST programs and objectives, with special emphasis on OST's FAs. It focuses on the effectiveness and efficiency of the CLN as a mechanism to incorporate diverse stakeholder concerns into the technology development process. The performance indicators used in this analysis were developed on the basis of prior research and the current stated goals and objectives of the CLN. 
Chapter 2 describes the methods employed in this research, including the development of performance indicators, the selection of respondents, how data were collected through interviews with and surveys administered to CLN volunteer participants and a purposive sample of FA staff, and how the data were analyzed. In Chapter 3 , we discuss the history, mission, and activities of the CLN, how it has evolved, and how it is organized and structured. Chapter 4 presents the findings of the research the perceptions of CLN's participants and its FA beneficiaries of the CLN's effectiveness and efficiency with respect to the three principal objectives of the CLN. Finally, Chapter 5 summarizes the key findings from Chapters 3 and 4 and recommends future directions for the CLN. 



\section{RESEARCH METHODS}

This research began in early February 1997 with a thorough examination of all available written materials concerning this program (e.g., Urban Energy and Transportation Corporation 1997a, b, c, and d; Kirwan-Taylor, et al. 1996; and U.S. Department of Energy 1996). The literature reviewed consisted of: descriptions of CLN mission, history, and activities prepared by DOE and its contractors; lists of CLN participants; collections of participants' comments; meeting summaries and detailed notes prepared by DOE and contractors for each CLN workshop and for selected planning committee meetings and Focus Area (FA) subgroup meetings; and draft performance measures suggested by CLN participants and DOE staff for CLN, OST, and similar programs. These materials were used to provide background on CLN's operations and to identify the program's major objectives so that relevant attributes of success and measurable performance indicators could be developed. Following the literature review, prospective subjects for this study were identified, data collection instruments were prepared and administered, and the resulting information was analyzed. Each of these major steps is discussed separately.

\section{SELECTION OF RESPONDENTS}

Because the CLN is relatively small and because we wanted good representation from all the different types of organizations whose members were involved in CLN activities, we attempted to interview all 34 volunteer participants. In addition, we approached eight paid staff with key roles in FA activities in order to obtain additional information on this critical component of CLN operations, selecting the technical lead and public participation coordinator for each FA. One individual was both an FA staffer and a CLN participant, but all of the other individuals selected for this study could be classified as either one or the other.

Of the universe of 34 CLN participants chosen for this study, oral interviews were conducted with 32 of them, for a response rate of approximately 94 percent. As shown in Fig. 2.1, more participants gave their primary organizational affiliation as general purpose state or local government than any other category. The next most highly represented group consisted of educators of all types, from the elementary grades through the university level. Environmental regulators and members of environmental or health advocacy groups came next in terms of numbers of participants, followed by business people and representatives of Native American tribal interests. The remaining organizational types each had two or less participants in the CLN. A complete listing of respondents and their organizational affiliations is provided in Appendix A.

All CLN participants were involved with one or more FAs, with 16 individuals involved with subsurface contaminants, 13 working with mixed waste, 12 participating in waste tank remediation efforts, and 9 associated with decommissioning and final disposition. The large majority of participants (nearly 70 percent) had been involved with the CLN for three years or longer, while another 13 percent had been involved for at least two years. Only one of the respondents had been involved with CLN for less than a year. Participants described many areas of expertise, with the greatest numbers describing themselves as having environmental, technical, governmental, regulatory, or public participation experience. When asked about the EM site with which they were most closely involved, more participants mentioned Fernald and Hanford than any other sites.

Interviews were completed with all eight of the FA staff who were selected to be interviewed. As expected, there was far less variation in primary organizational affiliation for this group than for CLN participants, with six FA staffers working for $D O E$ and the remaining two associated with DOE contractors. Also in contrast to CLN participants, nearly all FA staffers had been involved with the CLN for less than two years. The primary areas of expertise that they reported were technical, governmental, and managerial.

\section{DATA COLLECTION}

We designed this study in order to answer two basic questions that were important to the project sponsor: 


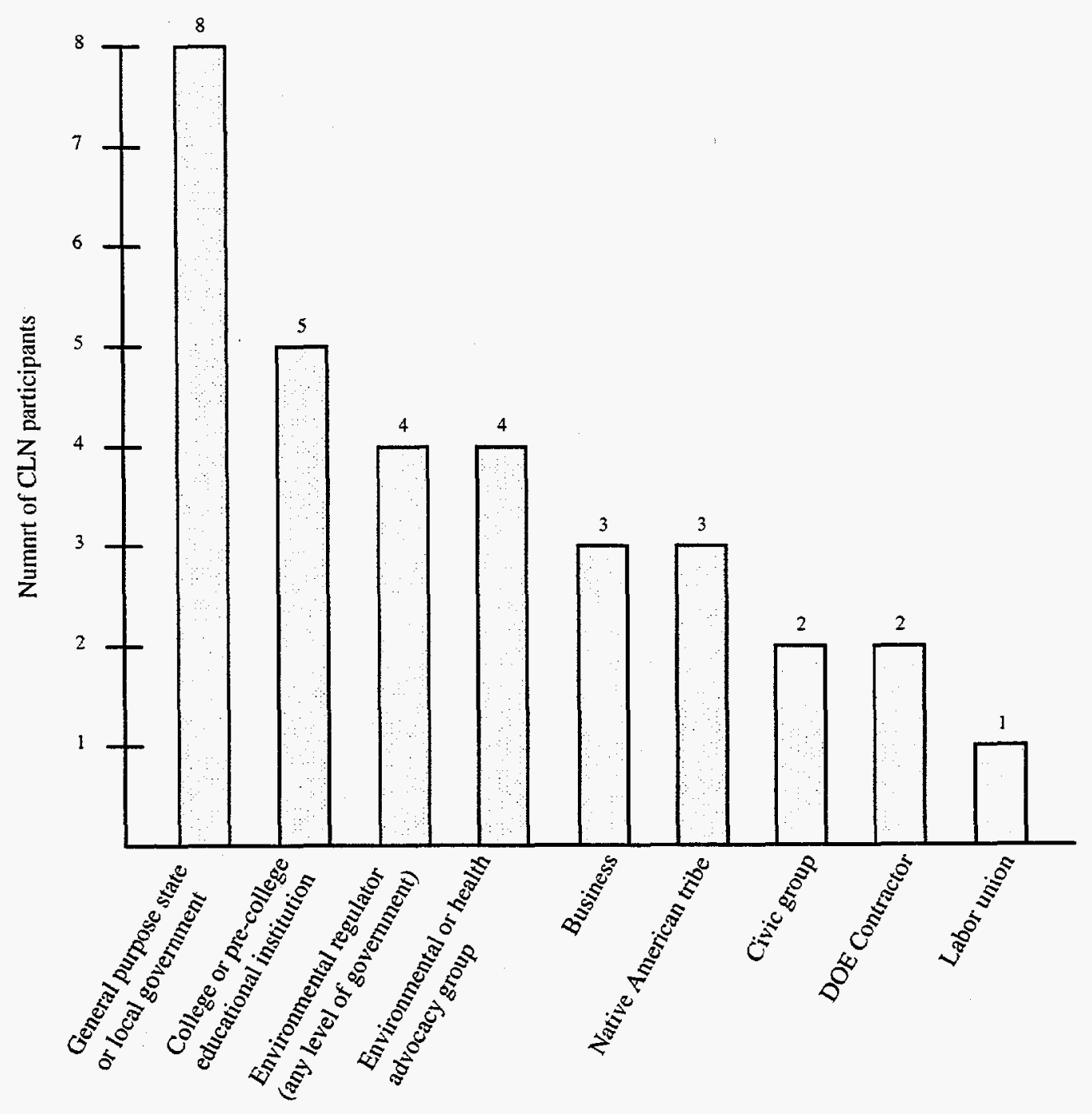

Fig. 2.1. Primary organizational affiliation of CLN participants 
- How useful is CLN from the perspective of the parties involved?

- How might CLN be changed to improve its usefulness?

To address this central issue of program usefulness, it was necessary to ascertain the basic purpose of the CLN, which we did through the literature review mentioned at the beginning of this chapter. Based on the materials we reviewed, we concluded that the CLN had three major objectives: to provide feedback and input to OST on technology development activities; to provide information on OST ideas and approaches to key stakeholder groups; and to provide input to OST on stakeholder concerns and involvement, which could involve consulting with OST on what issues are important to different interest groups and on how to design and implement public participation efforts. For each of these objectives, we developed a number of different performance indicators to measure from a variety of perspectives how well the objective had been satisfied. The performance indicators associated with each major CLN objective are shown in Table 2.1. Many of these indicators were borrowed, with modifications, from a recent ORNL study on how to evaluate public participation activities undertaken by the Office of Intergovernmental and Public Accountability in DOE's Office of Environmental Management (Carnes, Schweitzer, Peelle, Wolfe, and Munro 1996). Other indicators were developed especially for this project, but all of the indicators measured the perceptions of the parties involved in CLN rather than examining actual behaviors and events, because the amount of time available for this study was limited. And these indicators emphasized outcomes, which are tied to a program's basic objectives, rather than outputs, which focus on products with less regard to their significance (Frank 1996).

Based on the performance indicators and our need for information concerning key characteristics of the respondents themselves and ways in which the program could be improved, we developed two data collection instruments: an oral interview proto$\mathrm{col}$ and a written survey. The questions in the oral interview (Appendix B) were all open ended. These questions focused largely on gathering background information about the respondents and eliciting their input concerning possible improvements to the CLN, but the oral interview also asked about the usefulness of FA activities and about OST decisions and public involvement efforts on which the CLN has provided feedback and input. In contrast, the written survey (Appendix C) contained only standardized questions, all of them utilizing a fivepoint Likert-type scale. Each question in the written survey was keyed to a specific performance indicator and was designed to elicit the information needed to determine how well the CLN had done according to that measure. The survey was divided into three separate sections, each addressing one of the three major objectives described above. While all questions employed a five-point scale, not all the scales were identical. For most questions, " $l$ " and " 5 " represented the extreme end of opposite concepts (e.g., "very negatively" and "very positively") while " 3 " indicated no effect. For a few other questions, "1" stood for "none" or "not at all," "3" represented "moderately," and " 5 " meant "completely" or "very substantially."

Once the oral interview protocol and the written survey had been developed, they were reviewed by the project sponsor, the sponsor's support staff, and the leadership of the CLN. This review, which resulted in many thoughtful comments and substantial revision to the original instruments, served as a pretest. All of the oral interviews, with the exception of three face-to-face interviews held in the Oak Ridge area, were completed by telephone. As mentioned previously, interviews were conducted with 32 of the 34 CLN participants and with all $8 \mathrm{FA}$ staffers that were targeted. All of the interviews were completed during March 1997. Written surveys were completed by 29 CLN participants (for a response rate of 85 percent) and by all $8 \mathrm{FA}$ professionals. The surveys were sent out in March and all were returned by the first week in April.

\section{DATA ANALYSIS}

In order to get a clear and accurate picture of how CLN participants and FA staff perceived the program, the answers provided by these two groups were analyzed separately. 1 For the written survey, simple descriptive statistics (minimum value, maximum value, mean, and standard deviation) were generated for each survey question for each of the two separate sets of respondents. Answers within each major section of the written survey indicate 


\section{Table 2.1. Performance indicators to measure usefulness of CLN according} to each major objective

\section{Provide feedback and input to OST on technology development activities}

- Participants' evaluation of how well CLN participants represent all important stakeholder groups

- Participants' evaluation of the effects of CLN activities on the legitimacy of the process used by OST to make decisions on technology development activities

- Participants' evaluation of the effect of CLN activities on the legitimacy of OST decisions

- Participants' evaluation of the extent to which CLN activities have added to OST's understanding of the interests and concerns of key stakeholders

- Participants' evaluation of the effect of CLN activities on their trust and confidence in OST and its contractors

- Participants' evaluation of the effect of CLN activities on the quality of key OST decisions

- Participants' evaluation of how CLN activities have affected the speed at which new technologies that address important EM site needs are introduced and implemented

- Participants' evaluation of how CLN activities have affected the public acceptability of new technologies that address important EM site needs

- Participants' evaluation of how their involvement in Focus Areas has affected the CLN's ability to provide feedback and input to OST on technology development activities

- Participants' comparison of the usefulness of Focus Area involvement with the usefulness of CLN's other activities as a means of providing feedback and input to OST on technology development activities

\section{Provide information on OST ideas and approaches to key stakeholder groups}

- Participants' evaluation of the extent to which CLN activities have added to key stakeholder groups' understanding of OST's interests, concerns, and programs

- Participants' evaluation of how their involvement in Focus Areas has affected the CLN's ability to provide information on OST ideas and approaches to key stakeholder groups

- Participants' comparison of the usefulness of Focus Area involvement with the usefulness of CLN's other activities as a means of providing information on OST ideas and approaches to key stakeholder groups

Provide input to OST on stakeholder concerns and involvement

- List of public involvement programs/efforts on which CLN has provided input to OST

- Participants' evaluation of the value of information on stakeholder interests and priorities provided to OST by CLN

- Participants' evaluation of the value of information on designing and implementing stakeholder involvement efforts that CLN has provided to OST

- Participants' evaluation of how their involvement in Focus Areas has affected the CLN's ability to provide input to OST on stakeholder concerns and involvement

- Participants' comparison of the usefulness of Focus Area involvement with the usefulness of CLN's other activities as a means of providing input to OST on stakeholder concerns and involvement 
the perceived usefulness of the CLN according to each major objective.

Once the answers to the survey questions given by all respondents within each broad grouping (CLN participants and FA staff) were analyzed, each data set was further disaggregated according to key characteristics of the respondents. Separate analyses were run to see how the answers varied according to respondents' primary organizational affiliation, FA involvement, length of time associated with the $\mathrm{CLN}$, and area of expertise.

For most questions in the written survey, respondents were asked for their current perceptions as well as for how they would have answered the same question 18 months earlier. The differences between the mean responses to the two questions within each matched pair indicated how respondents' perceptions of the program had changed over the past 18 months. ${ }^{2}$

Turning to the information gathered through the open-ended questions of the oral interview protocol, the responses regarding FA usefulness were analyzed by grouping similar answers together and examining the different general types of replies and specific examples provided by the participants to clarify their responses. The questions regarding OST decisions and public involvement efforts on which CLN provided feedback and input were used to compile lists of the most commonly-mentioned types of decision and public involvement programs addressed by the CLN. Answers to the three openended questions on possible improvements to the CLN were used as a source of ideas, noting those replies that were given most frequently as well as less common but highly creative suggestions. For all open-ended questions of the oral interview proto$\mathrm{col}$, the analysis also examined responses provided during follow-up questions asked during the course of the interviews. 



\section{THE CLN: ITS HISTORY, MISSION, AND ACTIVITIES}

The process and form of the CLN has changed steadily since its first meeting in February, 1993. CLN has gradually expanded its roles in order to better provide stakeholder feedback and input to OST.

Some highlights of CLN activity and development include:

- first participation in an Office of Technology Development (OTD, now OST) internal review (March, 1994),

- developing its own internal organization and leadership (1995), and

- concentrating upon OST's four cleanup Focus Areas (FAs) and forming subgroups to follow each FA (1996).

As a continuing stakeholder involvement activity, CLN differs in both form and function from other public participation efforts within DOE's cleanup efforts. Although CLN sponsors have sought to obtain the perspectives of a number of different interests and groups, the CLN is organized to solicit individual rather than group ideas and comments. Unlike site-specific advisory boards (SSABs) or the Environmental Management Advisory Board, it is not chartered under the Federal Advisory Committee Act (FACA). CLN focuses on national rather than site-specific problems and has chosen to retain an informal structure and reporting system rather than adopt more formal ones. Its volunteers are invited and, except for travel expenses, unpaid. They are asked to devote significant time and travel to Washington, D.C., and to sites within the DOE complex to attend CLN meetings, planning sessions, and FA workshops.

The following sections discuss the CLN as it is now, its mission and charter, development and evolution of the CLN, and activities of the CLN as reported by CLN members and some of those who interact with them.

\section{CURRENT STATUS}

The evolution of CLN from its beginnings in 1992 has produced an interactive network involving 35 volunteer community leaders and various OST and DOE staff concerned with OST's technology development (TD) efforts. To paraphrase comments of one member of the CLN leadership, as it now functions, the CLN

- is a volunteer network of individuals acting as individuals,

- is a sounding board for OST,

- provides input to DOE on its technology development activities, usually informally in person and in trip reports,

- is not a FACAed-organization so does not make consensus decisions or develop c o n s e nsus recommendations,

- does not determine CLN's "representativeness," though CLN pushes for more stakeholder involvement at the site level, and

- receives widely varying feedback depending upon the receptivity of the DOE individuals or groups involved.

Other significant defining features of the CLN include the long tenure of a core group of members (from the beginning of the CLN), development of an internal leadership from this core group (providing significant institutional memory within the group and, now, within OST), and continuing priority given to the creation, development, and viability of CLN by the OST leadership.

Feedback and interaction occur directly between CLN members, OST leadership, and FA technical leaders. Two-way interaction between CLN members and OST staff has increased in response to CLN urging and the added specialization within CLN with FA subgroups. The number of one-way technical briefings has decreased accordingly.

CLN functioning and survival are strongly shaped by the characteristics listed above. Because CLN is organized as a network of individuals, the activities and input are highly individualized. Having decided in May, 1995, not to opt for a more formalized structure, CLN continues on a largely informal, person-to-person basis with communications directly among CLN participants, FA staff, and the OST leadership. This approach offers both advantages and problems: advantages have been the flexibility and innovative possibilities offered by 
the lack of formal structure, including ad hoc agreements between CLN participants and FA and OST staff for reviews and consultations on diverse program activities; disadvantages have included a lack of focus and organization seen in the early years of CLN as well as a lack of effort toward, or basis for, group accountability. Both of these disadvantages have frustrated some CLN members, as revealed in interviews.

Not being chartered under FACA limits the CLN's ability, as an organization, to seek consensus or to make collective recommendations. Alternatively, FACA requirements could seriously limit the flexibility and openneess within the group (e.g., frank and candid discussions within the CLN and with OST staff) that the CLN currently enjoys. FACA-chartered groups can evolve and adjust to changing circumstances only within fairly narrow or bureaucratically negotiated limits.

Because of this flexibility and informality, CLN has been able to evolve into an increasingly viable and useful organization, overcoming some of its early problems. The interest of the OST leadership and its attention to the CLN provided the multi-year time period required for this process to evolve and develop. This time, as an organizational development resource, has enabled CLN and OST to learn how they could interact in a useful fashion.

Significant amounts of time are required for both agency personnel and volunteer citizen stakeholders to learn new information as well as new skills. Citizens need time to absorb the large amounts of technical material and DOE organizational and operational details in the field of technology development. Technical managers and staff, likewise, require significant amounts of time and assistance to learn how to listen to and communicate with non-technical stakeholders. One of the CLN's main accomplishments, in fact, may be its development of a template for understandable, more usable presentations by technical staff to external stakeholders and successful use of these guidelines in recent briefings to the CLN. In addition, developing trusting relationships often requires repeated encounters between the same individuals over time. Thus, the continuous tenure of participants on the CLN has been a vital component of developing such relationships with OST staff; in fact, the ten- ure of CLN participants is, in some cases, longer than that of the OST staff, giving the CLN participants a greater sense of continuity in problem solving than their OST counterparts.

\section{MISSION AND CHARTER}

From the start, the OST leadership's vision for a community leaders network defined "CLN as the only avenue for national stakeholder input to the Technology Development program," to review and comment on OTD programs and activities. This orientation resulted in spending much effort reviewing specific cleanup technologies and occupied much of CLN's early years with one-way transmissions of information, as well as reviewing the broader OST technology development and deployment strategies.

Identifying strategies for improving public involvement was mentioned by CLN participants in 1993 and has evolved to a specific FA mission of monitoring public involvement strategy and implementation in the MWFA. An additional mission of disseminating information about CLN and OST back out to their organizations and agencies was added later. More attention was given in 1996 to OST policy, the overall problem domain of technology development, and strategies or "the big picture."

Various statements of the CLN mission exist. The five part mission, goals, and objectives statement presented in the CLN Workshop of June, 1996 , stipulated that the CLN mission as an informally structured stakeholder network assisting OST included:

- providing individual input on technology development issues in the EM focus areas,

- identifying stakeholders' concerns,

- providing feedback (both positive and negative) on technology development issues,

- establishing an ongoing dialogue on science and technology issues, and

- providing informed perspectives to CLN communities.

Like everything else in the CLN, its mission continues to evolve. For instance, one member characterized CLN as a market focus group for FAs, and 
the MWFA technical leader has referred to the MWFA's CLN subgroup conceptually as a "taxpayer board of directors."

\section{DEVELOPMENT AND EVOLUTION OF THE CLN}

As the technology development function changed in DOE in the past five years, so has the CLN. The Office of Technology Development (OTD) became the Office of Science and Technology (OST). The Integrated Demonstration program in OTD became five and then four waste-type FAs in 1995. Currently, OST's emphasis is shifting from technology development to technology deployment as EM implements the Ten Year Plan.

The idea of a CLN that developed during a workshop in 1992 resulted in the establishment and naming of the CLN in 1993. The original core group of 12 grew to 15 and finally to its current size (35) in 1996. According to current procedures, potential members are nominated by DOE site personnel, and issued two invitations to attend. Both members and nominees have been dropped for nonappearance at two consecutive meetings. Recent additions have increased tribal and labor representation as well as including participants from previously missing sites with significant EM activities, such as the Oak Ridge Reservation.

Communication among CLN participants and between CLN participants and DOE personnel occurs not only via face-to-face meetings but also via internet and web connections and access that have been developed and supplied to each participant. The CLN Home Page links participants, as well as the public, to the organization's mission statement, a factsheet, a brief history of the CLN, and a current list of CLN participants, as well as a CLN Information Room, the CLN FAs Room, the CLN Communications Room, and a CLN Research Room. Participants can file trip reports, speak directly to the OST leadership, take advantage of electronic mail capabilities, and, for some FAs, confer in a chat room.

A number of issues have been addressed by CLN participants on a recurring basis throughout the organization's existence. These include: mem- bership (including size, composition, and "representativeness" of the CLN); meeting locations (relative advantages of meeting at EM sites compared to meeting in Washington, D.C.); meeting agendas (e.g., depth vs. breadth of deliberations on issues and technologies and, more recently, the overall OST program as compared to FAs); public involvement issues; communication (including use of electronic communications and the internet); and the CLN's role and appropriate processes.

\section{CLN INTERNAL ORGANIZATION}

CLN's internal organization has evolved to an official internal planning group (self nominated) and elected officers. Early discussions of whether the membership should change and rotate or add to the initial core group have been resolved in favor of the latter. While the CLN does not set membership criteria, some have sought to make it more representative by suggesting adding labor and tribal members and have suggested specific persons to fill these categories.

Members have sought improvements to the focus of CLN and flow of tasks and meetings by having input to the agenda and organization of CLN meetings and activities. Through interaction with OST and contractor personnel, many of their suggestions have been implemented. Members comment that the information flow has become more two-way in the last two years, moving to more interactive activities rather than the earlier parade of technical presentations of the first two years. The emerging leadership roles have largely been filled by members of the original core group. At last count the Planning Committee had expanded to about half the entire group, causing some concern over unwieldy meetings, expense, and focus.

Although the Planning Committee has had major input to the agenda and the decision to concentrate on OST's four FAs, it has never handled its own budget and has had little knowledge of the CLN's expenses. There is also no arrangement for handling "action items" that result from CLN activities or meetings. 


\section{ACTIVITIES}

The CLN has organized much of its work around biannual general meetings, tours and demonstrations at diverse DOE sites throughout the complex, individual reviews and comments from CLN participants to OST staff and its leadership, and, more recently, according to the four FAs and the FA subgroups developed within the CLN. The locations, dates, and subjects of the biannual meetings of the CLN are identified in Table 3.1.

The CLN planning committee now helps schedule twice yearly general meetings with FA specialization or breakout sessions. Tours and demonstrations of particular technologies were scheduled throughout 1995-96. Workshop meetings with CLN subgroups are held with FA technical people. For instance, in the eight-month period preceding the June 1996 semi-annual meeting, 20 CLN participants attended no less than 24 meetings and workshops. This total included 17 internal meetings (three FA workshops, four technology demonstrations or program reviews, plus budget, peer and EM-50 program reviews) and 9 external meetings such as related conferences and professional and trade meetings. Budget cuts have begun to affect this pattern, however, and cancellations, delays and reduction of member travel have become common since mid-1996.

\section{CONCLUSIONS}

It was widely acknowledged by most participants and FA respondents that the CLN finally found its stride and role in the last 18 months. This period coincides with two developments - forming its own internal planning committee and finding a focus in 1996 with FA subgroups. After a lengthy education process, the group is taking more responsibility for the direction and pace of its efforts.

The basic function of the CLN appears to be to encourage interaction between CLN and technology development staff in DOE, thus exposing community leaders to the problems and constraints of OST and technology development, and exposing DOE's technical staff and managers to a variety of public and stakeholder perspectives.
Participants are concerned with the linkages among the CLN and other public and stakeholder involvement mechanisms within EM such as SSABs and STCGs. While the CLN has made contributions on both the national and site levels, its role between the levels remains ad hoc and undefined. Making the public involvement connection between the national level and the sites remains a challenge.

The CLN's incremental process of evolution and development, while seemingly slow and disorganized at times, has resulted in a set of arrangements and accumulated experience that has already had significant impact on OST managers relative to how they think and act about their programs. 
Table 3.1. Biannual meetings of the CLN

\begin{tabular}{|c|c|c|}
\hline Location & Dates & Principal activities and subjects \\
\hline San Diego, CA & $\begin{array}{l}\text { February } 8-10 \\
1993\end{array}$ & $\begin{array}{l}\text { - Integrated Demonstration Overview } \\
\text { - Assessment of Stakeholder Acceptability of Innovative Technology }\end{array}$ \\
\hline $\begin{array}{l}\text { Augusta, } \\
\text { GA }\end{array}$ & $\begin{array}{l}\text { August 16-17, } \\
1993\end{array}$ & $\begin{array}{l}\text { - Toured Savannah River Site Integrated Demonstration Project and } \\
\text { Defense Waste Processing Facility } \\
\text { - Provided feedback on OST Draft Strategic Plan and Draft EM Public } \\
\text { Participation Plan Outline }\end{array}$ \\
\hline $\begin{array}{l}\text { Gaithersburg, } \\
\text { MD }\end{array}$ & $\begin{array}{l}\text { March 7-10, } \\
1994\end{array}$ & $\begin{array}{l}\text { - Participated in OST Mid-Year Program Review } \\
\text { - Updated on status of SSABs } \\
\text { - Discussed OST's new approach to, and CLN role in, environmental } \\
\text { research and technology development }\end{array}$ \\
\hline San Diego, CA & $\begin{array}{l}\text { December } 4-6, \\
1994\end{array}$ & $\begin{array}{l}\text { - Transition to New Approach/Site Technology Coordination Groups } \\
\text { - Provided input on stakeholder strategy for the Contaminant Plume } \\
\text { Containment Focus Area }\end{array}$ \\
\hline $\begin{array}{l}\text { Washington, } \\
\text { D.C. }\end{array}$ & $\begin{array}{l}\text { March 19-21, } \\
1995\end{array}$ & $\begin{array}{l}\text { - OST leadership discussed challenges faced by OST, presented vision for } \\
\text { CLN involvement in the FAs, and led a discussion on the Galvin Task } \\
\text { Force Report on Alternative Futures for DOE National Laboratories } \\
\text { - FA managers provided overviews of their programs } \\
\text { - Framework for stakeholder involvement presented } \\
\text { - Discussed formation of subgroups and membership additions }\end{array}$ \\
\hline $\begin{array}{l}\text { Washington, } \\
\text { D.C. }\end{array}$ & $\begin{array}{l}\text { November } 14- \\
16,1995\end{array}$ & $\begin{array}{l}\text { - Six new CLN members were invited and participated in the workshop } \\
\text { - Formed eight new issue areas and subgroups to support their } \\
\text { advancement } \\
\text { - FA Managers discussed plans for CLN interaction in FY96 } \\
\text { - Selected new CLN Chair and Vice Chair }\end{array}$ \\
\hline $\begin{array}{l}\text { Washington, } \\
\text { D.C. }\end{array}$ & $\begin{array}{l}\text { June } 26-28 \\
1996\end{array}$ & $\begin{array}{l}\text { - Developed "path forward" for future interactions between FAs and CLN } \\
\text { subgroups } \\
\text { - Needs for increased communication between CLN and OST addressed } \\
\text { - Retreats planned for MWFA, SCFA, and DDFA to provide CLN } \\
\text { participants with detailed information on the issues and problems } \\
\text { confronting the FAs. }\end{array}$ \\
\hline $\begin{array}{l}\text { Washington, } \\
\text { D.C. }\end{array}$ & $\begin{array}{l}\text { January 9-10, } \\
1997\end{array}$ & $\begin{array}{l}\text { - Provided stakeholder input to the four strategies encompassed in the EM } \\
\text { Science and Technology draft Ten Year Plan. } \\
\text { - Observed and evaluated a technical briefing on Ceramicrete } \\
\text { incorporating presentation guidelines developed by CLN. } \\
\text { - Participated in break-out sessions with the four Focus Area subgroups. } \\
\text { - Added two new CLN participants; selected a new CLN Chair and Vice } \\
\text { Chair. } \\
\text { - Viewed CLN home page demonstration: www.uetc.org/cln }\end{array}$ \\
\hline
\end{tabular}





\section{PARTICIPANTS' PERCEPTIONS OF CLN}

The questions guiding this research were grouped by the three major program objectives identified in Chapter Two: (1) to provide feedback and input to OST on technology development activities; (2) to provide information on OST ideas and approaches to key stakeholder groups; and (3) to provide input to OST on stakeholder concerns and involvement. The written survey (Appendix C) elicited a substantial amount of data from CLN participants and paid Focus Area (FA) staff concerning their perceptions of the CLN's usefulness. In addition, the oral interviews provided some supplementary information on the comparative usefulness of respondents' FA involvement and the CLN's other activities.

While all questions on the written survey employed a five-point Likert-type scale, not all the scales were identical. For most questions, "3" represented no effect, while " 1 " and " 5 " represented the extreme end of opposite concepts (e.g., very negatively and very positively; greatly diminished and greatly increased). For a few questions, however, " 1 " represented none or not at all while " 5 " meant completely or very substantially; for these items, "3" stood for moderately rather than for no effect. The reader should note that in this second type of scale, all numbers other than one and five indicate a more positive response than the same number would indicate in the first kind of scale.

As noted earlier, separate analyses were run to see how the answers varied according to respondents' primary organizational affiliation, FA involvement, length of time associated with the CLN, and area of expertise. For the CLN participant data set, disaggregating by organizational affiliation and FA involvement yielded the most interesting results. In contrast, disaggregating by length of involvement was much less useful because most respondents had been active for roughly the same period of time. And looking for patterns by expertise was largely fruitless because most respondents identified two or three different areas of experience. For the FA data set, none of the disaggregations proved useful, in large part because the number of respondents was relatively small and the variation on certain key dimensions (i.e., organizational affiliation and length of time involved with CLN) was minimal.

This chapter discusses, first with respect to information obtained through interviews and secondly through the written survey, respondents' current perceptions of CLN's success, changes in this perceived success over time, and perceptions by key subsets of CLN participants. Each of these major topics is addressed in a separate section and, within each section, the performance of CLN relative to each of the program's three objections is described.

\section{INTERVIEW RESULTS}

When asked about CLN's role in providing input to 1) key OST decisions and 2) public participation plans, members gave a wide variety of answers in accord with their varying interests and activity levels.

Input to Key OST decisions. Answers concerned member input to specific programs and plans as well as overall strategy. Many participants mentioned their involvement in consideration of the the Office of Environmental Management's Ten Year Plan, PEGs, IRPs, mid-year and end-of-year reviews. As to technology selection, CLN participants provided input to criteria for deciding among technologies, to ranking and prioritization exercises, and to reviews of particular technologies after witnessing demonstrations. Some participants mentioned the importance of the criteria reviews and prioritization as underpinnings to budget decisions.

While most participants seem to understand or believe that they have input and affect decisions about technology selection, a few participants said they had no role in technology selection or budgets, suggesting some difference of opinion or interpretation about whether CLN has control or merely influence on these decisions. Several mentioned input to and effect upon draft public participation plans, broad stakeholder involvement, and overall OST strategy. 
In more general responses, one participant said that CLN helped OST frame decisions in two important respects - what should be decided and how to decide. CLN's general "decision support" functions were noted as including budgeting, information transfer, and planning. Another said that it was a CLN duty to "challenge OST's basic assumptions." One participant was more concerned with judging technology acceptability on its appropriateness in the local/tribal context rather than on whether it would work. Another participant noted "We insert the public perspective into their planning function."

FA technical leaders and public participation coordinators responded that they used their CLN subgroup for program formulation and budgeting. One FA reported changing its technology selection criteria as a result of extended interaction with its CLN participants. The FA manager specifically mentioned using CLN members for high level and strategic issues and excluding them from its budget discussions "because that's political and CLN should not be political." Perhaps more compelling, technical leaders for three out of the four FAs indicated that they would be willing to pay for the FA activities of the CLN out of their FA budgets if budgetary support for the CLN at headquarters disappeared.

Input to Specific Public Involvement Programs/ Efforts. Throughout their responses to our questions, CLN participants emphasized that bringing a public/stakeholder perspective to $\mathrm{DOE}$ managers and principal investigators was an extremely important function of the CLN. When asked about CLN input to specific public involvement programs or efforts, participants were concerned about making more use of the public and stakeholders in site technology coordinating groups (STCGs) and coordinating and rationalizing the use of SSABs, STCGs, and the CLN. Several had served as representatives of a FA or the CLN to outside groups or had helped review outside programs for their public involvement component.

In addition to the public participation activity or plans on which OST requested input, some activity was individually initiated and implemented. One participant listed 12 activities to which she had made input, both within and outside of OST.

\section{SURVEY RESULTS - CURRENT PERCEPTIONS OF CLN'S SUCCESS}

In recognition of the possibility that CLN participants could have different impressions of the program than do paid FA staffers, the data provided by these two types of respondents were analyzed separately. This section describes the findings from these separate analyses and then notes key similarities and differences concerning how CLN participants and FA staff perceived the program's success.

\section{CLN Participants' Mean Response to Survey Items}

Objective 1: To provide feedback and input to OST on technology development activities. In general, the performance indicators associated with this objective received higher marks from CLN participants than did the measures related to either of the other objectives (Table 4.1). CLN participants were most enthusiastic about the program's performance in adding to OST's understanding of the interests and concerns of key stakeholder groups. On this item, the mean score was 4.34 , with 4 indicating a substantial addition to OST's understanding and 5 indicating a very substantial addition. OST participants also gave the program a relatively high score regarding how well the mix of CLN participants represents interested stakeholder groups (3.93, with 4 indicating substantially). In addition, CLN participants gave relatively high marks to CLN's effects on the legitimacy of OST's decision-making process and on respondents' trust and confidence in OST. Respondents' gave their lowest marks to the effect of CLN on the speed at which new technologies are introduced and implemented, with a mean score of 3.45 (roughly halfway between neither slowed nor accelerated and accelerated somewhat ). When asked specifically about FA activities, respondents were strongly positive (4.64) about the effect of their FA involvement on CLN's ability to provide feedback and input to OST on technology development. They also said, on average, that their FA involvement was somewhat more useful than their other CLN activities as a means of satisfying Objective 1. 
Table 4.1 Mean responses to all survey items by CLN participants and Focus Area staff

\begin{tabular}{lcc}
\hline & CLN & FA \\
& participants & staff \\
Performance indicators & $(N=29)$ & $(\mathrm{N}=8)$ \\
\hline
\end{tabular}

Objective 1. Usefulness of CLN as means of providing feedback and input to OST on technology development activities

1. Representativeness of CLN Participants

$\begin{array}{ll}3.93 & 3.75 \\ 4.28 & 3.63 \\ 3.83 & 3.50 \\ 4.34 & 4.25 \\ 4.10 & 3.25 \\ 3.84 & 3.50 \\ 3.45 & 3.13 \\ 3.75 & 3.63 \\ 4.64 & 4.38 \\ 4.09 & 4.57\end{array}$

10. Usefulness of FA involvement compared with usefulness of CLN's other activities concerning technology development

2. Effect on legitimacy of OST's decision-making process

3. Effect on legitimacy of OST decisions themselves

4. Addition to OST's understanding of stakeholder interests/concerns

5. Effect on trust and confidence in OST

6. Effect on quality of key OST decisions

8. Effect on public acceptability of new technologies

9. Effect of FA involvement on CLN's ability to provide feedback/input to OST on technology development

Objective 2. Usefulness of CLN as means of providing information on OST ideas and approaches to key stakeholder groups

1. Addition to stakeholders' understanding of OST issues/concerns/programs

2. Effect of FA involvement on CLN's ability to provide information on OST ideas to key stakeholders

3. Usefulness of FA involvement compared with usefulness of CLN's other activities concerning providing information on OST ideas to key stakeholders

Objective 3. Usefulness of CLN as means of providing input to OST on stakeholder concerns and involvement

1. Value of information provided to OST on stakeholder interests/ priorities

2. Value of information provided to OST on designing/implementing stakeholder involvement efforts

3. Effect of FA involvement on CLN's ability to provide input to OST on stakeholder concerns and involvement

4. Usefulness of FA involvement compared with usefulness of CLN's other activities concerning providing input to OST on stakeholder concerns/involvement

\footnotetext{
a Not all of the five-point scales used in the survey were identical. For items 1 and 4 under Objective 1 , item 1 under Objective 2 , and items 1 and 2 under Objective 3 , all numbers other than " 1 " and " 5 " indicate a more positive response than the same number would indicate for all other items.
} 
Objective 2: To provide information on OST ideas and approaches to key stakeholder groups. The performance indicators associated with this objective received lower scores than did the measures associated with either Objective 1 or Objective 3 . The question about the extent to which CLN activities have added to stakeholders' understanding of OST's interests, concerns, and programs received a much lower mean score than an analogous question under Objective 1 that asked about CLN's effect on OST's understanding of stakeholder interests. And the two questions regarding FA activities received lower scores than the questions addressing the same topic for the other two objectives.

Objective 3: To provide input to OST on stakeholder concerns and involvement. CLN participants, on average, gave relatively high marks to the value of information provided by CLN to OST on stakeholder interests and priorities as well as on designing and implementing stakeholder involvement efforts (3.82 and 3.86, respectively, with 4 indicating "substantial" value). These scores, while relatively high, did not indicate the same level of enthusiasm shown for the highest rated items under Objective 1. When asked about their FA involvement, respondents credited this with having a positive effect on CLN's ability to provide input to OST on stakeholder concerns and involvement (mean of 4.34) and also indicated that FA involvement was more useful than other CLN activities in terms of satisfying Objective 3 (3.77 with 4 being "somewhat more useful").

\section{FA Staffers' Mean Response to Survey Items}

Objective 1. Like the CLN participants described above, FA staffers gave higher scores to the performance indicators associated with Objective 1 than to those measures related to the other two objectives. But almost without exception, the mean scores for FA staff were lower than those for CLN participants (Table 4.1). However, the enthusiasm shown for CLN's effect on OST's understanding of stakeholders' interests and concerns (mean of 4.25 with 4 being substantial) was considerable, and the representativeness of CLN participants also was given a relatively high score ( 3.75 on the same scale). The effect of CLN on the speed at which new technologies are introduced received the lowest rating (3.13), but this was only slightly higher than the mean score given to CLN's effect on trust and confidence in OST (3.25). When asked about FA activities, respondents were quite positive about the effect of their FA involvement (4.38), but even more enthusiastic (4.57) about the usefulness of their FA involvement compared to their other CLN activities as a means of satisfying Objective 1 .

Objective 2. FA staff gave low marks (mean of 2.81 ) to CLN's performance in terms of adding to stakeholders' understanding of OST's interests, concerns, and programs. They were considerably more positive when it came to rating the worth of FA involvement, but even these items received lower scores than did analogous measures associated with the other two objectives.

Objective 3. FA staffers rated the value of information provided by CLN to OST on stakeholder interests and priorities as roughly halfway between moderate and substantial (3.44), while the value of CLN-provided information on designing and implementing stakeholder involvement efforts was seen as moderate (mean of 3.0 ). When asked about the effects and comparative usefulness of FA involvement, respondents' mean scores were somewhat higher.

\section{Comparison of CLN and FA Responses}

Both sets of respondents tended to give higher ratings to the performance indicators associated with Objective 1 than to those measures related to the other two objectives (Fig. 4:1), indicating their belief that the CLN was most successful in providing feedback and input to OST on technology development activities. In contrast, items associated with Objective 2 got the lowest scores from both sets of respondents, indicating that the CLN was perceived as least successful in providing information on OST ideas and approaches to key stakeholder groups.

Under all three objectives, CLN participants gave higher mean responses than did FA staff to every survey question except those comparing the usefulness of participants' FA involvement with the usefulness of CLN's other activities. Not surprisingly, the ratings given on these comparative questions by FA staff were considerably higher than 


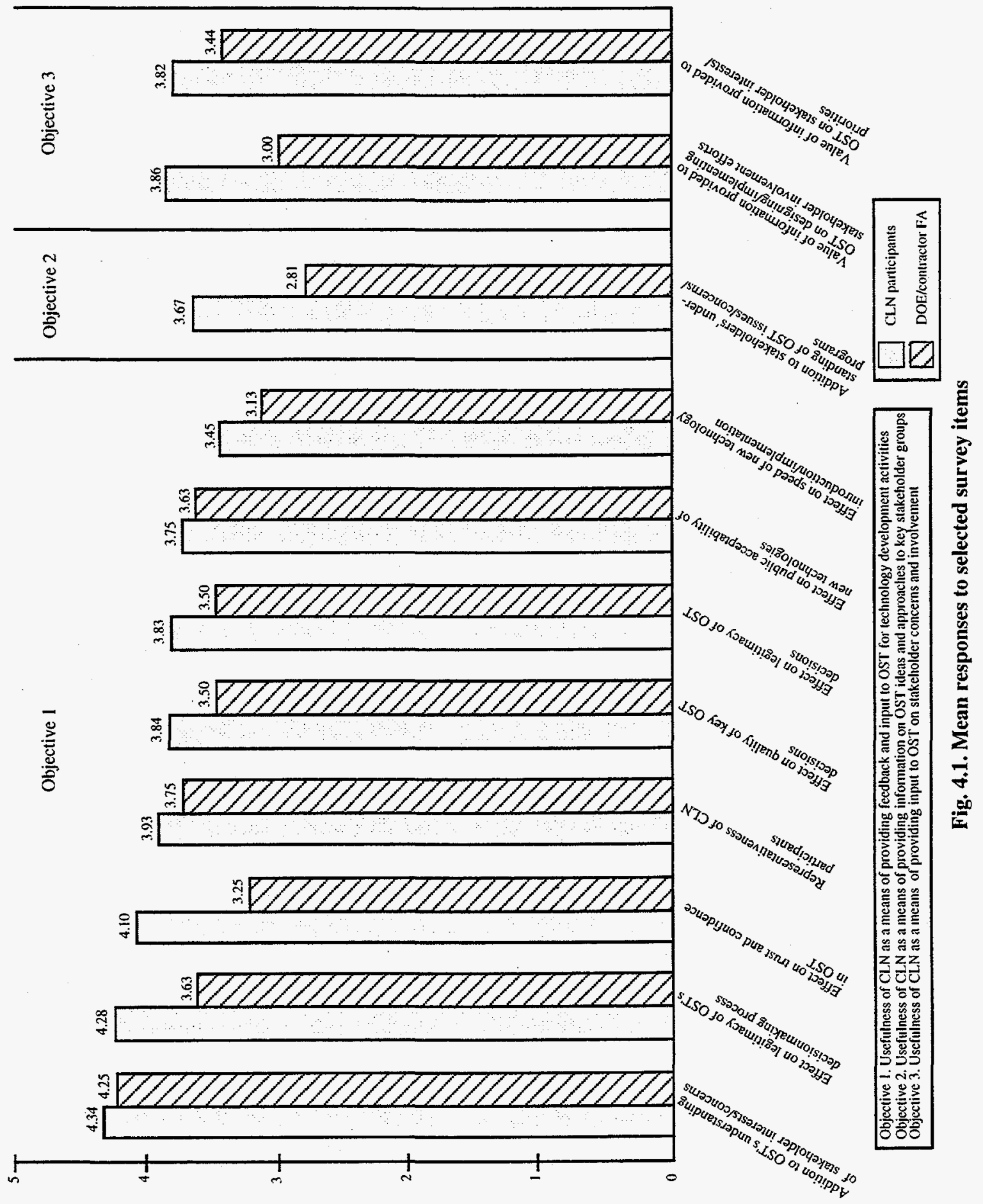


those given by CLN participants (Fig. 4.2); the interviews revealed that at least one-half of the CLN participants felt that their involvement with FA activities was much more useful than other CLN activities, and three-fourths of the FA representatives agreed. However, both sets of respondents reported that participants' involvement in FA activities had a positive effect on achieving all three objectives.

Under Objective 1, both CLN participants and FA staff gave the program high marks in terms of adding to OST's understanding of stakeholders' interests and concerns and for being representative of all interested parties. Another commonality between the two sets of respondents was that each gave their lowest rating to the CLN's effect on speeding up the introduction and implementation of new technologies. Unlike CLN participants, FA staff also gave low marks to CLN's effect on their trust and confidence in OST officials and contractors. The two sets of respondents also differ substantially in their perceptions of how CLN has affected the legitimacy of OST's decision-making process, with CLN participants having a much more positive view of this than did FA staff. Under Objective 2, CLN participants were likewise much more positive about the extent to which CLN activities have added to stakeholders' understanding of OST's interests, concerns, and programs. And for Objective 3, CLN participants gave much higher scores to the value of information provided to OST on designing and implementing stakeholder involvement efforts.

\section{CHANGES IN PERCEIVED SUCCESS OVER TIME}

While the previous section examined respondents' current perceptions of the CLN, this one focuses on the difference between these current impressions and how people say they would have responded to the same item 18 months earlier. The previously-discussed measures concerning FA involvement are not included in this discussion because the newness of FA activities kept us from asking for a retrospective rating of their usefulness. Once again, findings from the analyses of CLN participants and paid FA staffers are presented separately, and key differences between the perceptions of the two groups are noted.

\section{CLN Participants' Reported Changes}

Objective 1. Table 4.2 shows CLN participants' self-reported changes over time in their perceptions of the CLN. The increase in mean scores over the 18 month period ranges from a low of 0.45 to a high of 1.10 , with no measure getting a current rating that is lower than the one it would have received 18 months earlier. The indicator showing the most dramatic improvement over the 18 month period is CLN's addition to OST's understanding of the interests and concerns of key stakeholder groups. Two other measures that showed substantial increases are the effect on the legitimacy of OST's decision-making process and the effect on trust and confidence in OST. In all these cases, the dramatic increase is associated with a high current rating rather than with an especially low past score.

Objective 2. The extent to which CLN added to stakeholders' understanding of OST's interests and concerns showed a marked increase over the 18 month period, exhibiting a greater increase than most of the measures associated with Objective 1 . This is chiefly attributable to the fact that the mean score given on this item for the period 18 months prior to the survey was exceptionally low.

Objective 3. Both of the items shown under this objective in Table 4.2 show substantial growth over the 18 month period in question. This is due in part to the relative magnitude of current ratings and is also attributable in part to the low scores given on these items 18 months earlier.

It is important to note that the relative order of the ratings given the three objectives was the same for both time periods, with Objective 1 tending to receive the highest marks and Objective 2 receiving the lowest.

\section{Change in FA Staffers' Responses}

Objective 1. As shown in Table 4.2, FA staff showed a greater change in their perceptions over time than did CLN participants on nearly every performance indicator. The specific items showing the greatest growth under Objective 1 were the same three discussed above for the CLN participants plus one additional measure: the effect of CLN on the legitimacy of OST decisions. For three of these 


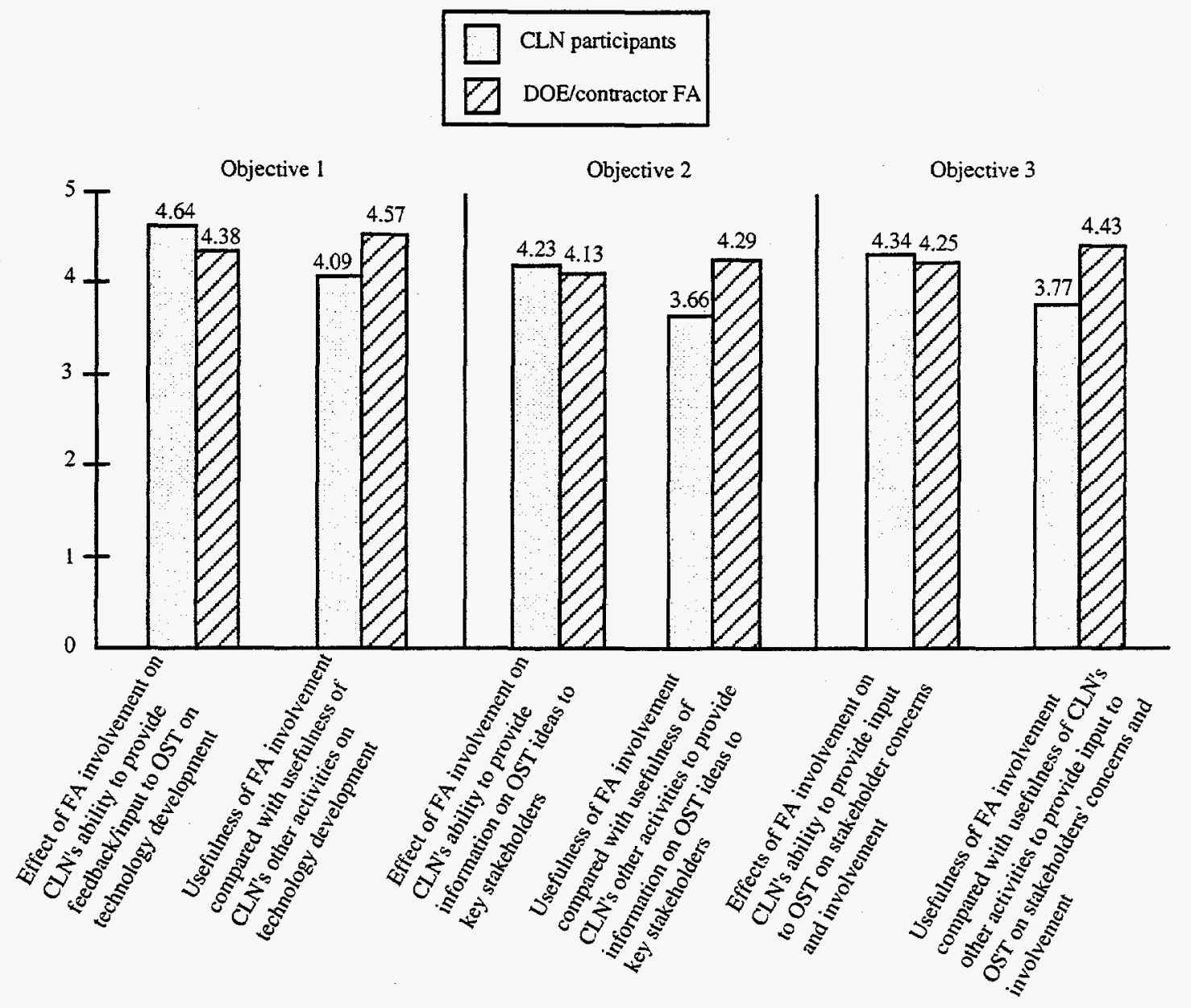

Objective 1 Usefulness of CLN as a means of providing feedback and input to OST for technology development activities Objective 2. Usefulness of CLN as a means of providing information on OST ideas and approaches to key stakeholder groups Objective 3. Usefulness of CLN as a means of providing input to OST on stakeholder concerns and involvement

Fig. 4.2. Mean responses to survey items addressing Focus Area involvement 
Table 4.2 Mean changes ${ }^{a}$ over time for CLN participants and Focus Area staff

\begin{tabular}{|c|c|c|}
\hline Performance indicators & $\begin{array}{c}\text { CLN } \\
\text { participants } \\
(\mathbb{N}=29)\end{array}$ & $\begin{array}{c}\text { FA } \\
\text { staff } \\
(N=8)\end{array}$ \\
\hline \multicolumn{3}{|c|}{$\begin{array}{l}\text { Objective 1. Usefulness of CLN as means of providing feedback and input to OST on technology development } \\
\text { activities }\end{array}$} \\
\hline 1. Representativeness of CLN Participants & +0.61 & +0.62 \\
\hline 2. Effect on legitimacy of OST's decisions-making process & +0.96 & +1.03 \\
\hline 3. Effect on legitimacy of OST decisions themselves & +0.67 & +0.90 \\
\hline $\begin{array}{l}\text { 4. Addition to OST's understanding of stakeholder interests } \\
\text { /concerns }\end{array}$ & +1.10 & +1.65 \\
\hline 5. Effect on trust and confidence in OST & +0.85 & +0.92 \\
\hline 6. Effect on quality of key OST decision & +0.56 & +0.70 \\
\hline $\begin{array}{l}\text { 7. Effect on speed of new technology introduction/implemen- } \\
\text { tation }\end{array}$ & +0.45 & +0.13 \\
\hline 8. Effect on public acceptability of new technologies & +0.47 & +0.43 \\
\hline \multicolumn{3}{|c|}{$\begin{array}{l}\text { Objective 2: Usefulness of CLN as means of providing information on OST ideas and approaches to key } \\
\text { stakeholder groups }\end{array}$} \\
\hline $\begin{array}{l}\text { 1. Addition to stakeholders' understanding of OST issues } \\
\text { /concerns/programs }\end{array}$ & +0.75 & +0.71 \\
\hline \multicolumn{3}{|c|}{ Objective 3: Usefulness of CLN as means of providing input to OST on stakeholder concerns and involvemer } \\
\hline $\begin{array}{l}\text { 1. Value of information provided to OST on stakeholder in- } \\
\text { terests/priorities }\end{array}$ & +0.88 & +1.24 \\
\hline $\begin{array}{l}\text { 2. Value of information provided to OST on designing/im- } \\
\text { plementing stakeholder involvement efforts }\end{array}$ & +0.90 & +1.20 \\
\hline
\end{tabular}

a Mean change over time is calculated by taking the mean response to Part a of each question (current perceptions) and subtracting the mean response to Part $b$ of the same question (how respondent would have answered 18 months earlier. 
four indicators, the magnitude of change over time was due primarily to the low ratings given 18 months previously, rather than to an exceptionally high current score. The one exception is CLN's addition to OST's understanding of stakeholder interests and concerns, which was characterized by a very high current rating as well as by a low past score. Despite the relatively low past scores, the performance indicators associated with Objective 1 still received higher ratings for the period 18 months prior to the survey than did the measures related to the other two objectives.

Objective 2. The mean score given to CLN's addition to stakeholders' understanding of OST's interests and concerns increased moderately, but this was mainly due to the extremely low scores given this item for the period 18 months prior to the survey.

Objective 3. Both of the items shown under this objective in Table 4.2 show substantial growth over the 18 month period in question but, once again, this is mainly due to the low scores given on these items 18 months earlier rather than on exceptionally high current ratings. In fact, these past ratings were so low that Objective 3 was rated slightly lower than Objective 2 , a reversal of respondents' perceptions reported as current at the time of the survey.

\section{Comparison of Change among CLN Par- ticipants and FA Staff}

For both the CLN participants and FA staff, mean changes over time were positive for all performance indicators (Fig. 4.3). According to both sets of respondents, the CLN showed the greatest improvement over time on five items: addition to OST's understanding of stakeholder interests and concerns; effect on legitimacy of OST's decision-making process; effect on trust and confidence in OST; value of information provided to OST on designing and implementing stakeholder involvement efforts; and value of information provided to OST on stakeholder interests and priorities.

On nearly every item, the mean responses by FA staff showed greater change over time than did the answers given by CLN participants. Under each objective, substantial changes in the ratings given by FA staff were primarily due to the low scores conferred for the period 18 months prior to survey completion, rather than to high current scores. This also was true for CLN participants for measures under Objective 3 that changed dramatically over time, but substantial change by CLN participants on items associated with Objective 1 can largely be credited to high current ratings. While the performance indicators associated with Objective 1 tended to receive the highest scores from CLN participants and FA staff during both time periods covered on the survey, the relative ranking by FA staff of Objectives 2 and 3 was reversed over time, with Objective 2 appearing to be slightly more important to FA staffers 18 months prior to the survey (although both items received very low scores at that time).

\section{PERCEPTIONS BY KEY SUBSETS OF CLN PARTICIPANTS}

As mentioned in Chapter 2, the CLN participant and FA staff data sets were disaggregated to see how respondents' answers varied according to their primary organizational affiliation, the FA(s) with which they were involved, their length of time in association with the CLN, and their area of expertise. For the CLN participant data set, disaggregating by organizational affiliation and FA involvement yielded the most interesting results and these findings are presented in separate subsections, below. As explained earlier, none of the disaggregations proved useful in understanding the responses provided by FA staff, primarily because of the small number of respondents and the limited variation on the characteristics that were examined. Therefore, the remainder of this chapter describes CLN participants only.

\section{Primary Organizational Affiliation of CLN Participants}

Table 4.3 shows mean responses and changes over time for all survey questions, disaggregated by respondents' primary organizational affiliation. Only four organizational types are shown in this table - and are discussed in the accompanying text - because the number of respondents was too small for all other categories to allow meaningful analysis. Even the numbers of respondents in each of the categories used here are so small that one should be cautious about making generalizations 

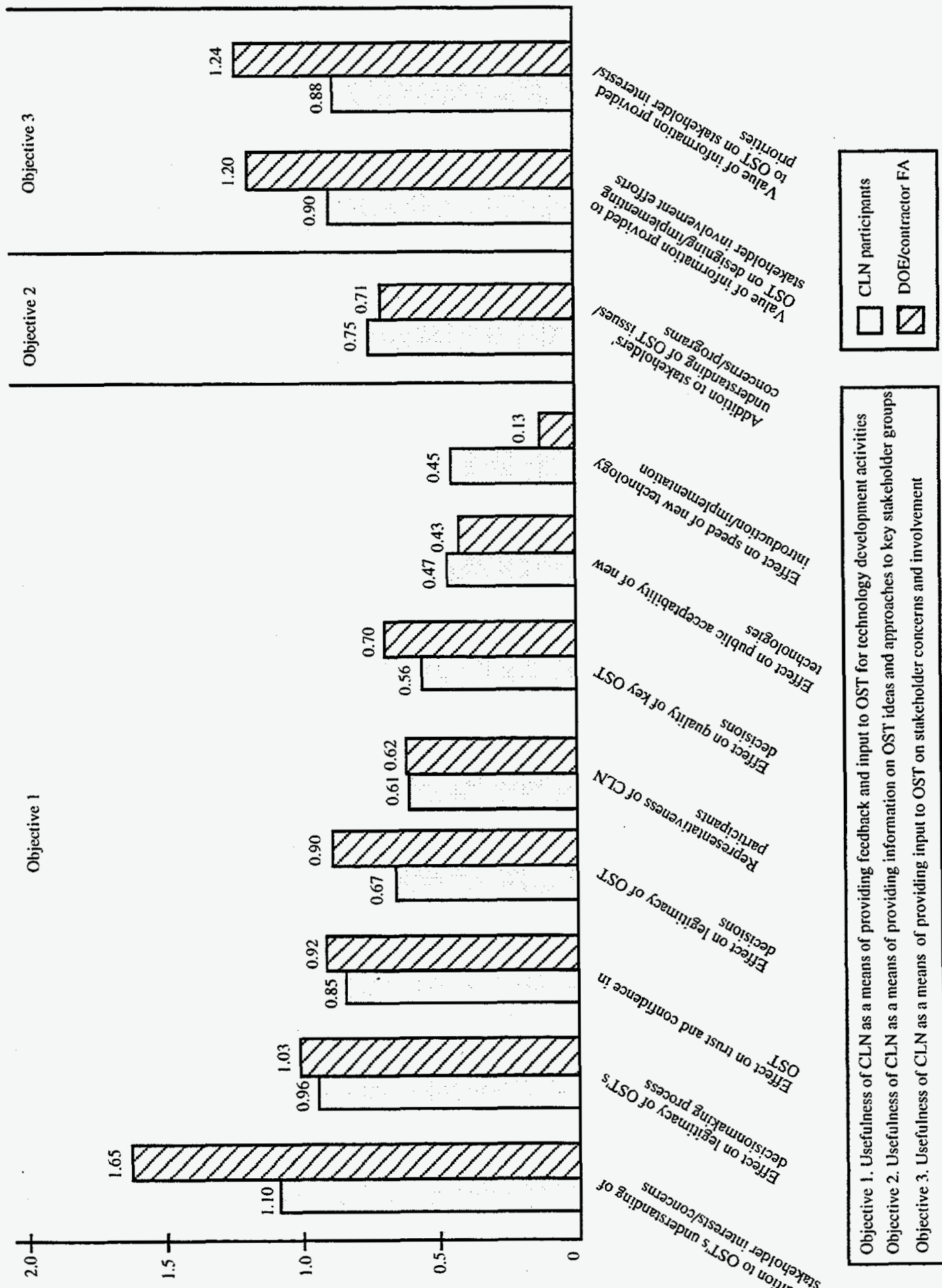

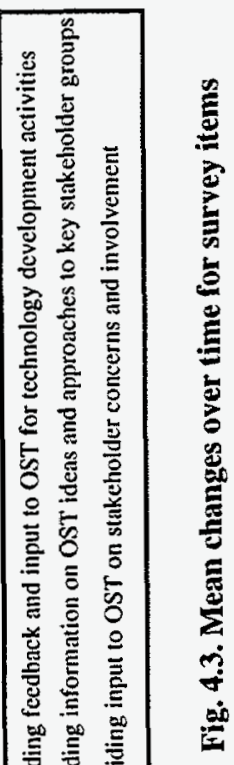


Table 4.3. CLN participants' survey responses, by primary organizational affiliation

\begin{tabular}{|c|c|c|c|c|c|c|c|c|}
\hline \multirow[b]{2}{*}{ Performance indicators } & \multicolumn{2}{|c|}{$\begin{array}{c}\text { General government } \\
(\mathrm{N}=8)\end{array}$} & \multicolumn{2}{|c|}{$\begin{array}{c}\begin{array}{c}\text { Educators } \\
(\mathrm{N}=5)\end{array} \\
\end{array}$} & \multicolumn{2}{|c|}{$\begin{array}{c}\text { Environmental regulators } \\
(\mathrm{N}=4)\end{array}$} & \multicolumn{2}{|c|}{$\begin{array}{c}\text { Indian Tribes } \\
(\mathrm{N}=3)\end{array}$} \\
\hline & $\begin{array}{l}\text { Mean } \\
\text { response }\end{array}$ & $\begin{array}{l}\text { (Mean } \\
\text { change) } a\end{array}$ & $\begin{array}{l}\text { Mean } \\
\text { response }\end{array}$ & $\begin{array}{l}\text { (Mean } \\
\text { change) } a\end{array}$ & $\begin{array}{l}\text { Mean } \\
\text { response }\end{array}$ & $\begin{array}{l}\text { (Mean } \\
\text { change) a }\end{array}$ & $\begin{array}{l}\text { Mean } \\
\text { response }\end{array}$ & $\begin{array}{l}\text { (Mean } \\
\text { change) }\end{array}$ \\
\hline \multicolumn{9}{|c|}{ Objective 1. Usefulness of CLN as means of providing feedback and input to OST on techology development activities } \\
\hline 1. Representativeness of CLN participants & 3.88 & +0.38 & 4.00 & +0.60 & 4.25 & +1.25 & 3.33 & +0.33 \\
\hline 2. Effect on legitimacy of OST's decision-making process & 4.63 & +1.13 & 4.40 & +1.00 & 4.25 & +0.92 & 3.67 & +1.67 \\
\hline 3. Effect on legitimacy of OST decisions thenselves & 4.25 & +0.87 & 3.60 & +0.60 & 3.75 & +0.42 & 3.33 & +1.33 \\
\hline 4. Addition to OST's understanding of stakeholder interests/concerns & 4.63 & +1.13 & 4.40 & +1.20 & 4.75 & +1.75 & 2.67 & +1.17 \\
\hline 5. Effect on trust and confidence in OST & 4.25 & +0.87 & 4.40 & +1.00 & 4.00 & +1.33 & 3.67 & +1.17 \\
\hline 6. Effect on quality of key OST decisions & 4.13 & +0.63 & 4.20 & +0.60 & 3.75 & +1.08 & 3.67 & +0.67 \\
\hline 7. Effect on speed of new technology introduction/implementation & 3.38 & +0.25 & 3.80 & +0.60 & 3.75 & +0.75 & 2.67 & +0.67 \\
\hline 8. Effect on public acceptability of new technologies & 4.00 & +0.50 & 3.80 & +0.80 & 3.75 & +0.42 & 3.00 & no change \\
\hline $\begin{array}{l}\text { 9. Effect of FA involvement on CLN's ability to provide feedback/ } \\
\text { input to OST on technology development }\end{array}$ & 4.88 & $\ldots$ & 4.80 & $\ldots$ & 4.75 & $\ldots$ & 3.67 & ... \\
\hline $\begin{array}{l}\text { 10. Usefulness of FA involvement compared with usefulness of CLN's } \\
\text { other activities concerning technology development }\end{array}$ & 4.25 & $\ldots$ & 4.40 & $\ldots$ & 3.50 & $\ldots$ & 2.33 & -... \\
\hline \multicolumn{9}{|c|}{ Objective 2. Usejilness of CLN as means of providing information on OST ideas and approaches to key stakeholder grotus } \\
\hline 1. Addition to stakeholders' understanding of OST issues/concerns/programs & 4.13 & +1.19 & 4.20 & +1.00 & 3.75 & +0.42 & 3.00 & +1.00 \\
\hline $\begin{array}{l}\text { 2. Effect of FA involvement on CLN's ability to provide information } \\
\text { on OST ideas to key stakeholders }\end{array}$ & 4.38 & $\ldots$ & 4.60 &.-- & 4.00 &.-- & 3.50 & $-\ldots$ \\
\hline $\begin{array}{l}\text { 3. Usefulness of FA involvement compared with usefulness of CLN's } \\
\text { other activities concerning providing information on OST ideas to } \\
\text { key stakeholders }\end{array}$ & 3.75 & $\ldots$ & 3.40 & $\ldots$ & 3.50 & $\ldots$ & 2.00 & .... \\
\hline \multicolumn{9}{|c|}{ Objective 3. Usefulness of CLN as means of providing input to OST on stakeholder concerns and involvement } \\
\hline $\begin{array}{l}\text { 1. Value of information provided to OST on stakeholder } \\
\text { interests/priorities }\end{array}$ & 4.13 & +0.88 & 3.80 & +0.80 & 4.50 & +1.17 & 3.3 .3 & +1.83 \\
\hline $\begin{array}{l}\text { 2. Value of information provided to OST on designing/ } \\
\text { implementing stakeholder involvement efforts }\end{array}$ & 4.38 & +1.00 & 4.00 & +1.20 & 4.50 & +0.83 & 2.67 & +1.17 \\
\hline $\begin{array}{l}\text { 3. Effect of FA involvement on CLN's ability to provide input to } \\
\text { OST on stakeholder concerns and involvement }\end{array}$ & 4.50 & $\ldots$ & 4.40 & - - - & 5.00 & $\ldots$ & 3.33 & $\cdots$ \\
\hline $\begin{array}{l}\text { 4. Usefulness of FA involvement compared with usefulness of CLN's } \\
\text { other activities concerning providing input to OST on stakeholder } \\
\text { concerns/involvement }\end{array}$ & 3.69 & $\ldots$ & 3.60 & $\ldots$ & 3.75 & $\ldots$ & 2.00 & $\cdots$ \\
\hline
\end{tabular}

a Mean change over time is calculated by taking the mean response to part a of each question (current perceptions) and subtracting the mean response to part b of the same question (how respondent would have answered 18 months earlier). 
From these findings concerning the perceptions and priorities of people belonging to these types of organizations.

Objective 1. The ratings given by members of Native American tribes are lower - and usually much lower - than those associated with any other organizational type for every survey question. In contrast, the scores given by members of general government and by educators tend to be higher than those provided by the other respondents. However, two items received relatively high ratings from all respondents: the effect of CLN activities on the legitimacy of OST's decision-making process; and the effect of FA involvement on CLN's ability to provide feedback and input to OST on technology development. Another measure, CLN's addition to OST's understanding of stakeholder interests and concerns, received very high marks by all groups except for Indian tribes, which gave it a fairly low rating. It is also noteworthy that tribal members, in contrast to all other respondents, found FA involvement to be somewhat less useful than CLN's other activities as a means of providing feedback and input to OST on technology development activities. Items that increased substantially in importance over time for all major organizational types were: CLN's effect on the legitimacy of OST's decision-making process; CLN's addition to OST's understanding of stakeholder interests and concerns; and CLN's effect on trust and confidence in OST.

Objective 2. The ratings given to the effect of FA involvement on CLN's ability to provide information on OST ideas to key stakeholders were

relatively high for all major organizational types. But once again, tribal members found FA involvement to be somewhat less useful than CLN's other activities as a means of achieving this objective. The ratings given for CLN's addition to stakeholder understanding of OST issues and concerns increased substantially over time for all groups except environmental regulators.

Objective 3. The scores associated with two performance indicators - value of information provided to OST on designing and implementing stakeholder involvement efforts, and the effect of FA involvement on CLN's ability to provide input to OST on stakeholder concerns and involvement - were very high for all groups except Indian tribes. And, as with the other two objectives, tribal participants found FA involvement to be somewhat less useful than CLN's other activities as a means of achieving this objective. Finally, the ratings given to the value of information provided to OST on stakeholder interests and priorities and the value of information provided to OST on designing and implementing stakeholder involvement efforts increased substantially over time for all major organizational types.

\section{CLN Participants' Focus Area Involvement}

In Table 4.4, mean responses and changes over time are presented for all survey questions, disaggregated by the FA with which respondents are involved. Several respondents are affiliated with more than one FA, and that is reflected in the number of respondents shown at the top of each column in the table. It should be noted that the number of respondents falling into each category is greater than the numbers for each key organizational type discussed in the preceding subsection.

Objective 1. A review of the disaggregated responses shows that no single FA gave consistently higher or lower ratings than the other FAs for all performance indicators associated with Objective 1 . However, the Decommissioning and Disposition (D\&D) FA and the Tank Remediation FA gave much higher ratings than the other FAs did on the usefulness of their FA involvement compared with the usefulness of CLN's other activities. In addition, the $D \& D$ group's mean score was noticeably lower than that of the other FAs' on CLN's effect on the legitimacy of OST decisions. All FAs gave high scores to four items: CLN's effect on the legitimacy of OST's decision-making process; CLN's addition to OST's understanding of stakeholder interests and concerns; CLN's effect on trust and confidence in OST; and the effect of FA involvement on CLN's ability to provide feedback and input to OST on technology development. The scores for the first two of these items grew substantially for all four FAs over the 18 month period addressed by the survey. Two other items - CLN's effect on the speed of new technology introduction and implementation, and CLN's effect on the public acceptability of new technologies - had ratings by all the FAs that grew relatively slowly over time. 
Table 4.4. CLN participants' survey responses, by Focus Area involvement

\begin{tabular}{|c|c|c|c|c|c|c|c|c|}
\hline \multirow[b]{2}{*}{ Performance indicators } & \multicolumn{2}{|c|}{$\begin{array}{c}\text { Decommissioning and } \\
\text { Disposition }(\mathrm{N}=9)\end{array}$} & \multicolumn{2}{|c|}{$\begin{array}{l}\text { Mixed Waste } \\
(\mathrm{N}=10)\end{array}$} & \multicolumn{2}{|c|}{$\begin{array}{l}\text { Subsurface Contaminants } \\
\qquad(\mathrm{N}=14)\end{array}$} & \multicolumn{2}{|c|}{$\begin{array}{l}\text { Tank Remediation } \\
\quad(\mathrm{N}=12)\end{array}$} \\
\hline & $\begin{array}{c}\text { Mean } \\
\text { response }\end{array}$ & $\begin{array}{l}\text { (Mean } \\
\text { change) }\end{array}$ & $\begin{array}{c}\text { Mean } \\
\text { response }\end{array}$ & $\begin{array}{l}\text { (Mean } \\
\text { change) }\end{array}$ & $\begin{array}{c}\text { Mean } \\
\text { response }\end{array}$ & $\begin{array}{l}\text { (Mean } \\
\text { change) } a\end{array}$ & $\begin{array}{l}\text { Meain } \\
\text { response }\end{array}$ & $\begin{array}{l}\text { (Mean } \\
\text { change) } a\end{array}$ \\
\hline \multicolumn{9}{|c|}{ Objective 1. Usefulness of CLN as means of providing feedback and input to OST on techmology development activities } \\
\hline 1. Representativeness of CLN participants & 3.89 & +0.51 & 3.70 & +0.48 & 3.93 & +0.79 & 3.75 & +0.45 \\
\hline 2. Effect on legitimacy of OST's decision-Inaking process & 4.00 & +1.00 & 4.10 & +1.10 & 4.36 & +1.00 & 4.33 & +0.93 \\
\hline 3. Effect on legitimacy of OST decisions themselves & 3.56 & +0.68 & 3.90 & +1.01 & 3.86 & +0.72 & 4.00 & +0.80 \\
\hline 4. Addition to OST's understanding of stakeholder interests/concerns & 4.22 & +1.09 & 4.00 & +1.33 & 4.36 & +1.29 & 4.42 & +1.12 \\
\hline 5. Effect on trust and confidence in OST & 4.11 & +0.98 & 3.90 & +1.02 & 4.07 & +0.78 & 4.17 & +0.84 \\
\hline 6. Effect on quality of key OST decisions & 3.61 & +0.23 & 3.90 & +0.68 & 3.86 & +0.79 & 3.92 & +0.42 \\
\hline 7. Effect on speed of new technology introduction/implementation & 3.56 & +0.43 & 3.40 & +0.51 & 3.50 & +0.57 & 3.50 & +0.60 \\
\hline 8. Effect on public acceptability of new technologies & 3.44 & +0.31 & 4.00 & +0.67 & 3.71 & +0.50 & 3.73 & +0.33 \\
\hline $\begin{array}{l}\text { 9. Effect of FA involvement on CLN's ability to provide feedback/ } \\
\text { input to OST on technology development }\end{array}$ & 3.44 & $\ldots$ & 4.50 & $\ldots$ & 4.75 & $\ldots$ & 4.63 & $\ldots$ \\
\hline $\begin{array}{l}\text { 10. Usefulness of FA involvement compared with usefulness of CLN's } \\
\text { other activities concerning technology development }\end{array}$ & 4.33 & ... & 3.80 & $\ldots$ & 3.82 & $\ldots$ & 4.29 & $\ldots$ \\
\hline \multicolumn{9}{|c|}{ Objective 2. Usefiluess of CLN as means of providing information on OST ideas and approaches to key stakeholder groups } \\
\hline 1. Addition to stakeholders' understanding of OST issues/concerns/programs & s 3.28 & +0.47 & 3.60 & +0.82 & 3.71 & +1.10 & 3.88 & +0.73 \\
\hline $\begin{array}{l}\text { 2. Effect of FA involvement on CLN's ability to provide information } \\
\text { on OST ideas to key stakeholders }\end{array}$ & 4.11 & $\ldots$ & 4.40 & $\ldots$ & 4.04 & $\ldots$ & 4.50 & $\cdots$ \\
\hline $\begin{array}{l}\text { 3. Usefulness of FA involvement compared with usefulness of CLN's } \\
\text { other activities concerning providing information on OST ideas to } \\
\text { key stakeholders }\end{array}$ & 3.89 & $-\cdots$ & 3.70 & $\cdots$ & 3.61 & $\cdots$ & 3.68 & - - - \\
\hline \multicolumn{9}{|c|}{ Objective 3. Usefilthess of CLN as means of providing input to OST on stakeholder concerns and involvement } \\
\hline $\begin{array}{l}\text { 1. Value of information provided to OST on stakeholder } \\
\text { interests/priorities }\end{array}$ & 3.78 & +0.90 & 3.56 & +0.81 & 3.93 & +1.11 & 3.82 & +0.88 \\
\hline $\begin{array}{l}\text { 2. Value of information provided to OST on designing/ } \\
\text { implementing stakeholder involvement efforts }\end{array}$ & 3.56 & +0.68 & 3.89 & +1.14 & 4.07 & +1.00 & 3.64 & +1.08 \\
\hline $\begin{array}{l}\text { 3. Effect of FA involvement on CLN's ability to provide input to } \\
\text { OST on stakeholder concerns and involvement }\end{array}$ & 4.33 & - . - & 4.20 & - . & 4.29 & $\ldots$ & 4.42 & $\ldots$ \\
\hline $\begin{array}{l}\text { 4. Usefulness of FA involvement compared with usefulness of CLN's } \\
\text { other activities concerning providing input to OST on stakeholder } \\
\text { concerns/involvement }\end{array}$ & 4.17 & $\ldots$ & 3.50 & $\ldots$ & 3.79 & $\ldots$ & 3.59 & $\ldots$ \\
\hline
\end{tabular}

"Mean change over time is calculated by taking the mean response to part a of each question (current perceptions) and subtracting the mean response to part b of the same question (how respondent would have answered 18 months earlier). 
Review and Evaluation of the Office of Science and Technology's Community Leaders Network

Objective 2. The D\&D FA gave a substantially lower rating to CLN's addition to stakeholder understanding of OST issues and concerns than did the other three PAs. However, the D\&D group had the highest score on the comparative usefulness of FA involvement for achieving this objective. All GAs gave high ratings to the effect of FA involvement on CLN's ability to provide information on OST ideas to key stakeholders.

Objective 3. As with the other two objectives, all FAs gave high ratings to the effect of FA involvemont on the achievement of Objective 3. And, once again, the D\&D FA gave the highest score to the comparative usefulness of FA involvement, this time for providing input to OST on stakeholder concerns and involvement. In contrast, the ratings given to the value of information provided to OST on designing and implementing stakeholder involvement efforts grew substantially over time for all HAs except D\&D.

The final chapter of the report summarizes the key findings from this study and recommends stategies for maximizing CLN's usefulness in the tutore.

30 


\section{SUMMARY AND RECOMMENDATIONS}

This chapter provides a summary of key findings and our recommendations regarding how the effectiveness and efficiency of the CLN might be enhanced. Both the findings and recommendations are keyed to the objectives of the CLN.

\section{SUMMARY OF KEY FINDINGS}

The review and evaluation focused on how the CLN is currently perceived by both CLN participants and selected FA staff, and also on how it was perceived in the past; in other words, the evaluation takes into account the evolution of the organization. Coupling the evaluation with the CLN's evolution was important, as it turned out, because of significant changes in the structure and focus of the organization as it has changed over time. The story of the CLN as a developing or evolving organization is familiar:

- its beginning as a design and creation of the OST leadership,

- some groping about as the organiza-tion accumulated an organizational identity through its members' experiences, and

- members' demands for focus and accountability being met through participants' activities with OST's Focus Area and in the CLN participants' development of their own leadership.

As noted earlier, there are advantages and disadvantages to this style of organizational development. More formal structures, where objectives and responsibilities are clearly laid out, may be more efficient in some ways, but this same formality may hamper the development of collective ownership of the organization - effective and efficient organizations need to be developed on the basis of bottom-up activities of its members as well as topdown design, directives, and other management activities. For organizations composed of volunteers such as the CLN, where there is little but symbolic compensation, collective ownership of the organization by its participants may be one of several necessary (but not necessarily sufficient) conditions for success.

\section{Evolving Perceptions of CLN's Success}

The approach taken in this review and evaluation allowed us to examine how perceptions of CLN's success changed over time. Specifically, our interviews delved into the respondents' memory about what the CLN had accomplished with respect to the organization's principal objectives and the respondents' role in those accomplishments as well as how the organization might be improved with respect to those objectives. The survey form explicitly asked the respondents to characterize their current perceptions of the CLN with respect to the various performance indicators and, for many of the measures, how they would have characterized their perceptions 18 months ago.

\section{Objective 1: Provide feedback and input to OST on technology development activ- ities}

According to those we interviewed, the CLN has succeeded in terms of all three objectives, but the highest marks are for the first objective - to provide feedback and input to OST on technology development activities. Within this objective, the CLN participants and the FA representatives scored CLN participation highest for how it has increased OST understanding of interests and concerns of key stakeholder groups and lowest for speeding, or even facilitating, the introduction or implementation of new technologies. Both CLN participants and FA staff gave the program relatively high scores for being representative of all interested parties. CLN participants also gave relatively high marks to CLN's effect on the legitimacy of OST's decisionmaking process, and to the effects on respondents' trust and confidence in OST. The CLN participants scored their participation higher than did the FA representatives on all performance indicators except for the usefulness of FA involvement compared with CLN's other activities concerning technology development.

For nearly all performance indicators, changes in the perceived usefulness of the CLN in providing 
feedback and input to OST on technology development have been greater for representatives from FAs than for CLN participants. This difference is, however, almost entirely a function of significantly lower initial ratings given by (and, perhaps expectations held by) FA representatives to the potential usefulness of the CLN. It should be noted that all changes over time in the usefulness of the CLN with respect to this objective were positive things are only getting better - although the usefulness of the CLN in speeding technology introduction and implementation may not yet have had a significant test. Moreover, to the extent that the speed of future technology deployment is constrained by public and regulatory acceptance, it may not be fair to test the CLN, per se, on this measure since these deployments will be made in site-specific and problem-specific environs; at best, the CLN participants may provide OST with advance warning regarding the types of issues and concerns that may affect public and regulatory acceptance so that these issues and concerns are mitigated prior to actual deployment attempts.

Comparing FA and CLN-as-a-whole involvement. As noted earlier, the decision to direct CLN's attention to OST's Focus Areas (FAs) appears to mark a significant event in the life of the CLN. As noted in interviews with many CLN participants, the CLN seemed to be a network in search of a mission, and the FAs provided that mission. At least one-half of the CLN participants strongly felt that their involvement with $F A$ activities was much more useful than other CLN activities (e.g., biannual meetings, document and program reviews), and three-fourths of the FA representatives agreed. Most often, CLN participants indicated that nonFA activities within the CLN suffered from a lack of clear objectives, expectations, feedback, structure, and interactions, and that they had expected this kind of guidance from OST.

Objective 2: Provide information on OST ideas and approaches to key stakeholder groups

Despite some disagreement over whether this objective had formally been adopted for the CLN and the reporting of generally lower scores on performance indicators associated with this objective than the other two, many participants have dissemi- nated information to their own organizations and stakeholder groups and observed that the CLN should disseminate information more actively. Many of the CLN participants support continuing or increasing the use of electronic communications (e.g., the CLN Home Page and other links on the world wide web, electronic mail, and chat rooms) but feel that other information dissemination activities are needed to assure appropriate coverage. Some participants indicated that OST needed to help disseminate information, working perhaps through other channels such as the STCGs. On average, FA staff gave much lower marks to CLN's performance in terms of adding to stakeholders' understanding of OST issues, concerns, and programs than did CLN participants.

Objective 3: Provide input to OST on stakeholder concerns and involvement

Both CLN participants' and FA representatives' evaluation of CLN activities with respect to this objective were less favorable than for Objective 1 and more favorable than for Objective 2. Interviewees identified numerous stakeholder involvement programs and efforts with which they had been involved (e.g., STCGs, technology demonstrations, FA inputs, liaison to other groups, and the development of "Guides to Technical Presentations") but shared some concerns about the future of this objective; these included the need to share the volunteer load regarding involvement in multiple stakeholder involvement activities (e.g., STCGs and SSABs as well as the CLN) and the fact that the CLN participants speak as individuals and not as a unified group nor true representatives of groups or organizations to which they belong. On average, CLN participants gave much higher scores than did FA staff to the value of information provided to OST on designing and implementing stakeholder involvement efforts.

\section{CONCLUSIONS}

Our review and evaluation of the CLN has demonstrated mixed success. The CLN was perceived as most successful with respect to its first objective - providing feedback and input to OST on technology development activities - and least successful with respect to the second objective providing information on OST ideas and approaches 
to key stakeholder groups. The group's success was perceived differently by the group's members and its immediate and direct beneficiaries (as represented by FA representatives), with the CLN participants giving higher marks than the FA representatives on almost all performance indicators. This difference may be attributed to the self-interest of the CLN participants, or it may be attributed to the possibility that the members had and have a better ideas of what they are supposed to accomplish than do their beneficiaries. Even though the CLN members' perceptions of success are greater than those of the FA representatives, even those of the FA representatives are positive.

In its relatively brief existence, the CLN has had a unique and important role in OST's technology development activities - providing a linkage between the scientists, engineers, and decision-makers charged with the responsibility of developing technologies to solve DOE's environmental remediation and waste management problems with the rest of the world. Of course it can be argued and must be noted that this linkage is provided elsewhere - whatever technologies are developed must be deployed in the world, and that deployment is mediated by a host of decisions and decision-makers external to DOE, including federal and state regulatory regimes, the budgetary process, and other dimensions of public acceptance.

What appears to be unique to the CLN is its location or place within the problem domain of technology development. It should be understood that this place has not been achieved unilaterally. Its place appears to have been achieved through its experience rather than from any design or vision of the CLN (whether identified by OST's leadership, CLN participants, OST staff, or other persons or agencies). That is, institutionalization refers not to just the "bricks and mortar" of institution-building - the organization charts, budgets, agendas, meetings, tours, demonstrations, document reviews and associated products - but also, and more importantly, to the effort, enthusiasm, and energy expended by people of good will to learn about and work with each others' problems and concerns.

In a very real sense, the people of the CLN and OST represent the world on developing technology to solve DOE's legacy problems. If they can put together a team that understands and appreciates the interconnectedness of the physical, biological, and social systems and develop and design technologies responsive to the multiple and interactive dimensions of our problems, their successors have simply to implement or deploy, on a case-by-case or site-by-site basis, those technologies.

Of course, the CLN and OST team does not, cannot, and should not supplant other teams dedicated to solving the legacy problems of DOE. The case-by-case and site-by-site solutions, including technology deployments, constitute the real measure of success - the quantities of waste treated and disposed, the acres of land remediated for future uses, the magnitude of debt (of all kinds) reduced. Those solutions will be developed by other teams dedicated to solving specific problems. The CLN IOST team, however, can serve as a scout that lays out the broad strokes of the problem domain.

\section{RECOMMENDATIONS}

This review and evaluation of the CLN has identified numerous successes and partial successes and few real failures. In fact, almost by definition, volunteers cannot fail, although those responsible for optimizing volunteers' productivity and working with volunteers can do better. It is in this context that we offer the following recommendations.

According to CLN participants themselves and representatives of OST's FAs, the CLN has succeeded. Its attention to national, high-level, integrated policy issues, its attention to FAs for site input to problem sets, and its concern about the interplay between top-down and bottom-up communications and decision-making have all been hallmarks of the organization.

The future success of the CLN may depend on how a number of issues and concerns are addressed in the near future.

1. It is very important to make wise use of volunteer time and resources. The value of the expertise that OST has obtained from individual CLN participants would be significant in any case; the value of the expertise that OST has obtained from the CLN - the collective experience of CLN participants with OST and FAs - is much greater. In 
many ways, the CLN represents an institutional memory that is quite distinct from the remainder of OST's institutional memory but equally valid, long-lasting, and important.

2. The kinds and amounts of support services needed by the CLN and its participants are both important and, consistent with the increasing assumption of leadership by CLN participants, may best be identified by the CLN participants themselves. The CLN participants are busy volunteers with significant experience as volunteers and, in all cases, as professionals in what they do. These volunteers have already indicated their willingness to work, and they likely know best the kinds of support they need to make best use of their time.

3. If there were notes of caution and discomfort from the CLN participants, they tended to relate to a lack of attention by OST to their recommendations or, more simply, inadequate feedback regarding the worth of their deliberations. This failure by the OST leadership to communicate back to the CLN participants may seem to be characteristic of the informality and flexibility of the CLN, but it is a characteristic that is not conducive to success.

4. The CLN participants and some FA representatives focused on the need for better definition, integration, and coordination of stakeholder involvement activities within OST. There was certainly ample agreement regarding the need for coordination between the CLN and the STCGs, even recognizing the technically legitimate need to protect the independence of the STCGs as field-, rather than headquarters-directed activities.

5. As EM-50 begins its Technology Deployment Initiative (TDI), it would be prudent to reconsider the structure and activities of the CLN, the CLN FA subgroups, and other stakeholder involvement mechanisms (e.g., STCGs, SSABs, and the EMAB). Technology deployment has different stakeholder involvement needs than does technology development. More of the emphasis will inevitably be on acceptance of the developed technology by stakeholders - regulators and other stakeholders having influence over regulators. In a sense, at least for the TDI, the opportunity for stakeholder involvement in the design and development of technology has passed, although it may still be possi- ble for the CLN and other stakeholders to provide input to the permitted version of a technology.

6. As a mature stakeholder group, the CLN and its members should be asked how they would like the CLN to work, operate, and evolve in the future. Although OST cannot abandon its responsibility or accountability for OST activities or even for the CLN, it should be acknowledged that the CLN and its members now have significant institutional memory as compared with OST and the remainder of EM. OST might invite CLN participants to work with OST and the FAs to develop program plans and budgets for all CLN activities.

7. There are other improvements needed that may be outside the scope of OST. These include the definition and clarification of the roles of the CLN, the STCGs, the SSABs, the Environmental Management Advisory Board (EMAB), and the sites for stakeholder involvement for all EM activities, and the need for better communications among stakeholders at DOE sites with different programmatic sponsors or landlords (e.g., EM, Defense Programs, and Energy Research). 


\section{ENDNOTES}

1. The answers provided by the single respondent who was both a CLN member and a paid FA staffer were included in both data sets.

2. A longitudinal panel research design would be the preferred approach to determine changes in perception over time but was not possible given the structure of this project. Respondents' recall of past perceptions is imperfect, with experience during the 18 month lapse in time coloring respondents' perceptions of the past. However, respondents' imperfect recall, when aggregated in the research results, may not significantly affect the results. 


\section{REFERENCES}

Carnes, Sam A., Schweitzer, Martin, Peelle, Elizabeth, Wolfe, Amy K., and Munro, John F., 1996. Performance Measures for Evaluating Public Participation Activities in DOE's Office of Environmental Management, ORNL-6905. Oak Ridge, TN: Oak Ridge National Laboratory.

Frank, Barbara, 1996. Performance Measures in the EM Office of Technology Development, U.S. Department of Energy, Washington, D.C., June.

Kirwan-Taylor, H., et al., 1996. Enhancing Technology Acceptance: The Role of the Subsurface Contaminants Focus Area External Integration Team, PNNL-11224/BSRC-800/96/013/UC-602, Pacific Northwest National Laboratory, Richland, WA, September.

Office of Science and Technology, 1996. Proposed Performance Measures for the Office of Science and Technology, U.S. Department of Energy, Washington, D.C., June.

Urban Energy and Transportation Corporation, 1997a. Community Leaders Network Mission Statement, Washington, D.C., February [http://www.uetc.org/cln/mission.htm, 6/20/97].

Urban Energy and Transportation Corporation, 1997b. Community Leaders Network Factsheet, Washington, D.C., February [http://www.uetc.org/cln/factshet.htm].

Urban Energy and Transportation Corporation, 1997c. Community Leaders Network Subgroup

Descriptions, Washington, D.C., February [http://www.uetc.org/cln/faroom.htm].

Urban Energy and Transportation Corporation, 1997d. Community Leaders Network History, Washington, D.C., February [http://www.uetc.org/cln/history.htm]. 
APPENDIX A. LIST OF RESPONDENTS AND

ORGANIZATIONAL AFFILIATIONS 


\section{Respondents from the CLN}

William (Bill) Beck

Steele Environmental Resource Group

Hayburn, ID

\section{Jim Bierer}

Ross Local Schools

Hamilton, $\mathrm{OH}$

Richard Brusuelas, Director

Bernalillo County Environmental

Health Department

Albuquerque, NM

Curtis (Curt) S. Carlson

City of Kennewick

Kennewick, WA

Cory R. Chadwick, Air Quality Program Manager

Hamilton County Department of Environmental Services

Cincinnati, $\mathrm{OH}$

James A. (Jim) Cochran

Campus Dean

Washington State University at Tri-Cities

Richland, WA

Rico 0. Cruz, Environmental Specialist

Nez Perce Tribe

Department of Environmental

Restoration \& Waste Management

Lapwai, ID

Fred (Fritz) Daily

Butte, MT

Earl Leming, Director

Tennessee Department of Environment and Conservation

DOE Oversight Division

Oak Ridge, TN
Vicky Dastillung, Vice President

F.R.E.S.H., Inc.

Hamilton, $\mathrm{OH}$

Pamela (Pam) Dunn, Treasurer

F.R.E.S.H., Inc.

Harrison, $\mathrm{OH}$

Lorna Harrell

Butler County Soil and Water

Hamilton, $\mathrm{OH}$

Stuart Harris, Natural Resource Specialist

Confederated Tribes of the Umatilla Indian Reservation

Pendleton, OR

Albert M. (Al) Hodge, President

Metro Augusta Chamber of Commerce

Augusta, GA

George Jones

Plumbers \& Steamfitters

Knoxville, TN

Kelly Kaletsky, Environmental Monitoring Coordinator

Ohio EPA

Office of Federal Facilities Oversight

Dayton, $\mathrm{OH}$

Donald E. (Don) Kawal, Chairman

Greater Albuquerque Chamber of Commerce

Albuquerque, NM

Perjetta K. (PK) Smith

Nuclear Engineer

Westinghouse Savannah River Co.

Aiken, SC 
Betsy McBride

League of Women Voters/Public

Participation Network

Chesapeake, VA

Joel S. McTopy, Councilman

National Association of Counties

LaPlace, LA

Leland (Roy) Mink, Director

Idaho Water Resources Research Institute

University Of Idaho

Moscow, ID

Mary Jo Ondrechen, Professor

Chemistry Department

Northeastern University

Boston, MA

Bill Pardue

Oak Ridge, TN

William Paul Robinson, Research Director Southwest Research and Information Center Albuquerque, NM

Tom Schneider, Fernald Project Manager Ohio EPA

Office of Federal Facilities Oversight

Dayton, $\mathrm{OH}$

Raymond Sisneros

City/County Solid Waste Coordinator

City \& County of Santa $\mathrm{Fe}$

Santa Fe, NM
Curt Soper

Director of Agency Relations

The Nature Conservancy

Seattle, WA

Ginger Swartz

Swartz \& Associates

Boulder City, NV

Mervyn Tano, President

Tano and Associates

Denver, $\mathrm{CO}$

Eric P. Thompson, Executive Director

Lower Savannah Council of Governments

Aiken, SC

Audrey B. Watson

Garden Club of South Carolina

North Augusta, SC

Marvin W. (Marv) Weiss, President

Educational Consulting Services

Kennewick, WA

Jane Wittke, Environmental Communications

Coordinator

OKI Regional Council of Governments

Cincinnati, $\mathrm{OH}$ 


\section{Respondents from Focus Areas}

Julia Conner

DOE Idaho Operations

Technical Lead, Mixed Waste Focus Area

David W. Geiser

EM-53

Technical Lead, Tanks Focus Area

Paul W. Hart

Federal Energy Technology Center

Technical Lead, D\&D Focus Area

Cindy Malencia

DOE Savannah River Operations

Public Participation Coordinator, Subsurface

Contaminants Focus Area
Billie Mauss

DOE Richland Operations

Public Participation Coordinator, Tanks Focus Area

\section{Roger Scott}

Lockheed Martin Idaho Technologies, Co.

Public Participation Coordinator, Mixed

Waste Focus Area

Ginger Swartz (also CLN participant)

Swartz \& Associates

Public Participation Coordinator, D\&D Focus

Area

James Wright

DOE Savannah River Operations

Technical Lead, Subsurface Contaminants

Focus Area 
APPENDIX B. ORAL INTERVIEW PROTOCOL 
Oral Interview Protocol (3/10/97)

[Approximate time to administer: $30-40$ minutes]

I. Vital Information

[Collect any of the following that is missing and verify the rest]

1. Name:

2. Phone Number:

3. Fax Number:

4. Mailing Address:

5. E-Mail Address:

6. Organizational affiliation:

\section{Respondent's Background}

1. What is your position within your organization?

2. With which EM site or sites are you most closely involved?

3. How long have you been a participant in the CLN?

4. What particular expertise (e.g., governmental, environmental, regulatory, social, scientific, technical) do you bring to the CLN?

\section{Focus Area Involvement}

1. With which Focus Area(s) are you currently involved?

2. Compare the usefulness and productivity of your Focus Area activities with the usefulness and productivity of the activities in which the CLN engages as a whole.

\section{Key Types of OST Decisions on Which CLN Provides Feedback and Input}

1. What are the key types of OST decisions (e.g., technology selection, budgeting) on which CLN has provided feedback and input?

\section{Specific Programs on Which CLN Provides Feedback and Input}

1. Please list the specific public involvement programs and efforts on which CLN has provided feedback and input to OST.

\section{Possible Improvements to CLN [one question for each major objective]}

1. What changes could be made in the structure and/or activities of the CLN to increase the usefulness of the feedback and input it provides to OST on technology development activities?

2. What changes could be made in the structure and/or activities of the CLN to improve its ability to disseminate information on OST ideas and approaches to key stakeholder groups?

3. What changes could be made in the structure and/or activities of the CLN to increase the usefulness of the input it provides to OST on issues of importance to stakeholders and on how to design and implement stakeholder involvement efforts? 


\section{APPENDIX C. WRITTEN SURVEY}


Written Survey $(3 / 10 / 97)$

[Approximate time to complete: $15-20$ minutes]

\section{Usefulness of CLN as a Means of Providing Feedback and Input to OST on} Technology Development Activities

1. a. Using the following five-point scale, please indicate the extent to which the mix of CLN participants is representative of all key stakeholder groups with an interest in OST activities.

[1=not at all; 2=slightly; $3=$ moderately; $4=$ substantially; $5=$ completely $]$

b. If you were involved with the CLN 18 months ago, how would you have answered question la (above) at that time?

2. a. Using the following five-point scale, please indicate how the full set of CLN activities (including Focus Area involvement) has affected the extent to which OST's process for making technology development decisions is fair and serves the broad public interest.

[1=very negatively; $2=$ somewhat negatively; $3=$ neither negatively nor positively; $4=$ somewhat positively; $5=$ very positively]

b. If you were involved with the CLN 18 months ago, how would you have answered question 2a (above) at that time?

3. a. Using the following five-point scale, please indicate how the full set of CLN activities (including Focus Area involvement) has affected the extent to which OST decisions themselves are fair and serve the broad public interest.

[1=very negatively; $2=$ somewhat negatively; $3=$ neither negatively nor positively; $4=$ somewhat positively; $5=$ very positively]

b. If you were involved with the CLN 18 months ago, how would you have answered question 3a (above) at that time?

4. a. Using the following five-point scale, please indicate the extent to which the full set of CLN activities (including Focus Area involvement) has added to OST's understanding of the interests and concerns of key stakeholder groups.

[1=not at all; $2=$ slightly; $3=$ moderately; $4=$ substantially; $5=$ very substantially $]$

b. If you were involved with the CLN 18 months ago, how would you have answered question 4a (above) at that time?

5. a. Using the following five-point scale, please indicate how your CLN activities have affected the trust and confidence that you have in OST officials and associated contractors to perform their duties in a way that serves the broad public interest.

[ $1=$ greatly diminished; $2=$ somewhat diminished; $3=$ neither diminished nor increased; $4=$ somewhat increased; $5=$ greatly increased]

b. If you were involved with the CLN 18 months ago, how would you have answered question 5a (above) at that time? 
6. a. Using the following five-point scale, please indicate how the quality of key OST decisions (e.g., technology selection, budgeting) has been affected by the full set of CLN activities (including Focus Area involvement).

[1=very negatively; $2=$ somewhat negatively; $3=$ =neither negatively nor positively; $4=$ somewhat positively; $5=$ very positively]

b. If you were involved with the CLN 18 months ago, how would you have answered question $6 a$ (above) at that time?

7. a. Using the following five-point scale, please indicate how the full set of CLN activities (including Focus Area involvement) has affected the speed at which new technologies that address important EM site needs are introduced and successfully implemented.

[ $1=$ slowed greatly; $2=$ slowed somewhat; $3=$ neither slowed nor accelerated; $4=$ accelerated somewhat; $5=$ accelerated greatly $]$

b. If you were involved with the CLN 18 months ago, how would you have answered question 7a (above) at that time?

8. a. Using the following five-point scale, please indicate how the full set of CLN activities (including Focus Area involvement) has affected the public acceptability of new technologies that address important EM site needs.

[ 1 =greatly diminished; $2=$ somewhat diminished; $3=$ neither diminished nor increased; $4=$ somewhat increased; 5=greatly increased]

b. If you were involved with the CLN 18 months ago, how would you have answered question $8 \mathrm{a}$ (above) at that time?

9. Using the following five-point scale, please indicate how participants' involvement in Focus Areas has affected the CLN's ability to provide feedback and input to OST on technology development activities.

$[1=$ very negatively; $2=$ somewhat negatively; $3=$ neither negatively nor positively; $4=$ somewhat positively; $5=$ very positively]

10. Using the following five-point scale, please compare the usefulness of participants' Focus Area involvement with the usefulness of CLN's other activities as a means of providing feedback and input to OST on technology development activities.

[ $1=$ Focus Area involvement is much less useful; $2=$ Focus Area involvement is somewhat less useful; $3=$ Focus Area involvement and other CLN activities are about equally useful; 4=Focus Area involvement is somewhat more useful; 5=Focus Area involvement is much more useful]

II. Usefulness of CLN as a Means of Providing Information on OST Ideas and Approaches to Key Stakeholder Groups

1. a. Using the following five-point scale, please indicate the extent to which CLN activities have added to key stakeholder groups' understanding of OST's interests, concerns, and programs. [1=not at all; $2=$ slightly; $3=$ moderately; $4=$ substantially; $5=$ =ery substantially $]$ 
b. If you were involved with the CLN 18 months ago, how would you have answered question 1a (above) at that time?

2. Using the following five-point scale, please indicate how participants' involvement in Focus Areas has affected the CLN's ability to provide information on OST ideas and approaches to key stakeholder groups.

[ $1=$ very negatively; $2=$ somewhat negatively; $3=$ neither negatively nor positively; $4=$ somewhat positively; $5=$ very positively]

3. Using the following five-point scale, please compare the usefulness of participants' Focus Area involvement with the usefulness of CLN's other activities as a means of providing information on OST ideas and approaches to key stakeholder groups.

[1=Focus Area involvement is much less useful; 2=Focus Area involvement is somewhat less useful; 3=Focus Area involvement and other CLN activities are about equally useful; 4=Focus Area involvement is somewhat more useful; $5=$ Focus Area involvement is much more useful]

\section{Usefulness of CLN as a Means of Providing Input to OST on Stakeholder Concerns} and Involvement

1. a. Using the following five-point scale, please indicate the value of information on stakeholder interests and priorities that the CLN has provided to OST.

[ $1=$ none; $2=$ slight; $3=$ moderate; $4=$ substantial; $5=$ =xtremely substantial $]$

b. If you were involved with the CLN 18 months ago, how would you have answered question 1a (above) at that time?

2. a. Using the following five-point scale, please indicate the value of information on designing and implementing stakeholder involvement efforts that the CLN has provided to OST.

[1=none; $2=$ slight; $3=$ moderate; $4=$ substantial; $5=$ extremely substantial $]$

b. If you were involved with the CLN 18 months ago, how would you have answered question $2 \mathrm{a}$ (above) at that time?

3. Using the following five-point scale, please indicate how participants' involvement in Focus Areas has affected the CLN's ability to provide input to OST on stakeholder concerns and involvement. [1=very negatively; $2=$ somewhat negatively; $3=$ neither negatively nor positively; $4=$ somewhat positively; $5=$ very positively]

4. Using the following five-point scale, please compare the usefulness of participants' Focus Area involvement with the usefulness of CLN's other activities as a means of providing input to OST on stakeholder concerns and involvement.

[ $1=$ Focus Area involvement is much less useful; $2=$ Focus Area involvement is somewhat less useful;

$3=$ Focus Area involvement and other CLN activities are about equally useful; 4=Focus Area

involvement is somewhat more useful; $5=$ Focus Area involvement is much more useful] 
Internal Distribution

1-10. S. A. Carnes

11. G. E. Courville

12. S. G. Hildebrand

13. D.W. Lee

14. C. I. Moser

15. J. F. Munro

16-25 E. B. Peelle

26. R. M. Reed

27. D. E. Reichle

28. S. M. Schexnayder

29-38. M. Schweitzer

39. R. B. Shelton

40. B. E. Tonn

41. ORNL Patent Office

42. Central Research Library

43. Document Reference Section

44-45. Laboratory Records

46. Laboratory Records - RC

\section{External Distribution}

47. Dr. Lilia A. Abron, President, PEER Consultants, P.C., 1460 Gulf Blvd., 11th Floor, Clearwater, FL 34630

48. Dr. Don M. Beck, Acting Director, Office of Intergovernmental and Public Accountability, U.S. Department of Energy, EM-22, 1000 Independence Avenue, S.W., Washington, D.C. 20585

49. Mr. William Beck, Steele Environmental Resource Group, 807 West 500 South, Hayburn, ID 83336

50. Mr. Jim Bierer, Ross Local Schools, 407 Marcia Avenue, Hamilton, OH 45013

51. Mr. Gerald Boyle, Office of Science and Technology, U.S. Department of Energy, EM-50, 1000 Independence Avenue, S.W., Washington, D.C. 20585

52. Dr. Judith Bradbury, Pacific Northwest National Laboratory, 901 D Street, S.W., Suite 900 , Washington, D.C. $20024-2115$

53. Dr. Kristi Branch, Battelle Seattle Research Center, 4000 N.E. 41 St Street, Seattle, WA 98105

54. Mr. Richard Brusuelas, Director, Bernalillo County Environmental Health Department, 600 - 2nd Street, NW, Suite 500, Albuquerque, NM 87102

55. Mr. Curtis S. Carlson, City of Kennewick, PO Box 6242, Kennewick, WA 99336

56. Mr. Cory R. Chadwick, Air Quality Program Manager, Hamilton County Department of Environmental Services, 1632 Central Parkway, Cincinnati, OH 45210 
57. Mr. James A. Cochran, Campus Dean, Washington State University at Tri-Cities, 100 Sprout Road, Richland, WA 99352-1643

58. Ms. Julia Conner, U.S. Department of Energy, Idaho Operations Office, 765 Lindsay Blvd., Idaho Falls, ID 83401

59. Mr. Rico 0. Cruz, Environmental Specialist, Nez Perce Tribe, Department of Environmental Restoration \& Waste Management, Veterans Drive, PO Box 365, Lapwai, ID 83540

60. Mr. Fred Daily, 1408 Warren Ave, Butte, MT 59701

61. Ms. Vicky Dastillung, Vice President, F.R.E.S.H., Inc., 3088 Hamilton-Scipio Road, Hamilton, $\mathrm{OH} 45013$

62. Ms. Pamela Dunn, Treasurer, F.R.E.S.H., Inc., 7781 New Haven Road, Harrison, OH 45030

63-87. Mr. Tom Evans, Office of Science and Technology, U.S. Department of Energy, EM-53, Cloverleaf Complex, 19901 Germantown Road, Germantown, MD 20874-1290

88. Mr. Clyde W. Frank, Deputy Assistant Secretary for Science and Technology, U.S. Department of Energy, MS 5B-014, 1000 Independence Avenue, S.W., Washington, D.C. 20585

89: Mr. David W. Geiser, Office of Science and Technology, U.S. Department of Energy, EM-53, Cloverleaf Complex, 19901 Germantown Road, Germantown, MD 20874-1290

90. Ms. Lorna Harrell, Butler County Soil and Water, 686 Ridge Road, Taylor Mill, KY 41015

91. Mr. Stuart Harris, Natural Resource Specialist, Confederated Tribes of the Umatilla Indian Reservation, DNR/Special Service and Resources, P.O. Box 638, Pendleton, OR 97801

92. Mr. Paul W. Hart, Mailstop E02, U.S. Department of Energy, Federal Energy Technology Center, P.O. Box 880, Morgantown, WV 26507-0880

93. Ms. Elizabeth Heid, The Pew Charitable Trusts, One Commerce Square, 2005 Market Street, Philadelphia, PA 19103

94. Mr. Albert M. Hodge, President \& CEO, Greater Rome Chamber of Commerce, 1 Riverside Parkway, Rome, GA 30161

95. Mr. George Jones, Plumbers \& Steamfitters, 1216 Broadway, NE, Knoxville, TN 37917

96. Mr. Kelly Kaletsky, Environmental Monitoring Coordinator, Ohio EPA, Office of Federal Facilities Oversight, 401 East Fifth Street, Dayton, OH 45402-2911

97. Mr. Donald E. Kawal, Chairman, Greater Albuquerque Chamber of Commerce, 8701 Washington NE, P. O. Box 90850, Albuquerque, NM 87199

98. Mr. Earl Leming, Director, Tennessee Department of Environment and Conservation, DOE Oversight Division, 761 Emory Valley Road, Oak Ridge, TN 37830-7072 
99. Mr. Martin J. Letourneau, Office of Waste Management, U.S. Department of Energy, EM-35, 19901 Germantown Road, Germantown, MD 20874-1290

100. Ms. Cindy Malencia, U.S. Department of Energy, Savannah River Operations Office, Building 704-60H, Road 1, Aiken, SC 29801

101. Ms. Billie Mauss, U.S. Department of Energy, Richland Operations Office, EESB Building, 825 Jadwin Avenue, P.O. Box 550, Richland, WA 99352

102. Ms. Betsy McBride, League of Women Voters/Public Participation Network, 732 Watch Island Reach, Chesapeake, VA 23320

103. Mr. Joel S. McTopy, Councilman, National Association of Counties, 508 Chatsworth Drive, LaPlace, LA 70068

104. Dr. Leland Mink, Director, Idaho Water Resources Research Institute, 106 Morrill Hall, University Of Idaho, Moscow, ID 83843

105. Dr. Mary Jo Ondrechen, Chemistry Department, Northeastern University, 102 Hurtig Hall, Boston, MA 02115

106. ORNL Site Manager, U.S. Department of Energy, Oak Ridge National Laboratory, Post Office Box 2008, Oak Ridge, TN 37831-6269

107. Mr. Bill Pardue, 222 Connors Circle, Oak Ridge, TN 37830

108. Mr. Andy Paterson, Environmental Business International (EBI), 4452 Park Boulevard, Suite 301, San Diego, CA 92116

109. Mr. P. Richard Rittelmann, FAIA, Executive Vice President, Burt Hill Kosar Rittelmann Associates, 400 Morgan Center, Butler, PA 16001-5977

110. Mr. William Paul Robinson, Research Director, Southwest Research and Information Center, 105 Stanford SE, P.O. Box 4524, Albuquerque, NM 87106-4524

111. Mr. Tom Schneider, Fernald Project Manager, Ohio EPA, Office of Federal Facilities Oversight, 401 East Fifth Street, Dayton, OH 45402-2911

112. Mr. Roger Scott, Tribal and Public Programs, MWFA Program Office, PO Box 1625 , MS 3875, Idaho Falls, ID 83415

113. Mr. Raymond Sisneros, City/County Solid Waste Coordinator, City \& County of Santa Fe, P. O. Box 6152,2600 Galisteo Rd, Santa Fe, NM 87501

114. Ms. Perjetta K. Smith, Nuclear Engineer, Westinghouse Savannah River Co., P.O. Box 616, Building 707C, Aiken, SC 29808

115. Mr. Curt Soper, Director of Agency Relations, The Nature Conservancy, 217 Pine Street, Suite 1100 , Seattle, WA 98101

116. Ms. Ginger Swartz, Swartz \& Associates, 1547 Irene, Boulder City, NV 89005 
117. Mr. Mervyn Tano, President, Tano and Associates, 444 South Emerson, Denver, CO 80209

118. Mr. Eric P. Thompson, Executive Director, Lower Savannah Council of Governments, 2748 Wagener, Highway 302N, P.O. Box 850, Aiken, SC 29802

119. Dr. Susan F. Tierney, The Economics Resource Group, Inc., One Mifflin Place, Cambridge, MA 02138-4946

120. Dr. C. Michael Walton, Ernest H. Cockrell Centennial Chair in Engineering and Chairman, Department of Civil Engineering, University of Texas at Austin, Austin, TX 78712-1076

121. Ms. Audrey B. Watson, Garden Club of South Carolina, 910 River Oak Drive, North Augusta, SC 29841

122. Dr. Marvin W. Weiss, President, Educational Consulting Services, 3105 South Johnson Place, Kennewick, WA 99337

123. Ms. Jane Wittke, Environmental Communications Coordinator, OKI Regional Council of Governments, 801-B West Eighth Street, Suite 400, Cincinnati, OH 45203-1607

124. Mr. James Wright, U.S. Department of Energy, Savannah River Operations Office, Building 703-46A, Road 1, Aiken, SC 29801

125-26. OSTI, U.S. Department of Energy, P.O. Box 62, Oak Ridge, TN 37831 